Review

\title{
Advances in Hydrogen, Carbon Dioxide, and Hydrocarbon Gas Sensor Technology Using GaN and ZnO-Based Devices
}

\section{Travis Anderson ${ }^{1, *}$, Fan Ren ${ }^{2}$, Stephen Pearton ${ }^{3}$, Byoung Sam Kang ${ }^{1}$, Hung-Ta Wang ${ }^{1}$, Chih- Yang Chang ${ }^{1}$ and Jenshan Lin $^{3}$}

${ }^{1}$ Department of Chemical Engineering, University of Florida / Gainesville, FL 32611, USA

2 Department of Materials Science and Engineering, University of Florida / Gainesville, FL 32611, USA; E-Mail: ren@che.ufl.edu (F.R.)

${ }^{3}$ Department of Electrical and Computer Engineering, University of Florida / Gainesville, FL 32611, USA; E-Mail: spear@mse.ufl.edu (S.P.)

* Author to whom correspondence should be addressed; E-Mail: tjanderson@che.ufl.edu (T.A.); Tel.: +1-352-392-4727; Fax: +1-352-392-9513

Received: 22 April 2009; in revised form: 21 May 2009 / Accepted: 12 June 2009 / Published: 15 June 2009

\begin{abstract}
In this paper, we review our recent results in developing gas sensors for hydrogen using various device structures, including $\mathrm{ZnO}$ nanowires and GaN High Electron Mobility Transistors (HEMTs). ZnO nanowires are particularly interesting because they have a large surface area to volume ratio, which will improve sensitivity, and because they operate at low current levels, will have low power requirements in a sensor module. GaN-based devices offer the advantage of the HEMT structure, high temperature operation, and simple integration with existing fabrication technology and sensing systems. Improvements in sensitivity, recoverability, and reliability are presented. Also reported are demonstrations of detection of other gases, including $\mathrm{CO}_{2}$ and $\mathrm{C}_{2} \mathrm{H}_{4}$ using functionalized GaN HEMTs. This is critical for the development of lab-on-a-chip type systems and can provide a significant advance towards a market-ready sensor application.
\end{abstract}

Keywords: $\mathrm{GaN}$; $\mathrm{ZnO}$; gas sensors 


\section{Introduction}

The Gallium Nitride $(\mathrm{GaN})$ materials system is attracting much interest for commercial applications. Due to the wide-bandgap nature of the material, it is very thermally stable, and electronic devices can be operated to temperatures up to $500{ }^{\circ} \mathrm{C}$. The material is also chemically stable, with the only known wet etchant being molten $\mathrm{NaOH}$ or $\mathrm{KOH}$, making it very suitable for operation in chemically harsh environments or in radiation fluxes. Due to the high electron mobility, Nitride-based HEMTs can operate from very high frequency (VHF) through X-band frequencies with higher breakdown voltage, better thermal conductivity, and wider transmission bandwidths than Si or GaAs devices. GaN-based HEMTs can also operate at significantly higher power densities and higher impedance than currently used GaAs devices [1-16].

An overlooked potential application of the AlGaN/GaN HEMT structure is sensors. The high electron sheet carrier concentration of nitride HEMTs is induced by piezoelectric polarization of the strained $\mathrm{AlGaN}$ layer and the spontaneous polarization is very large in wurtzite III-nitrides. This provides an increased sensitivity relative to simple Schottky diodes fabricated on GaN layers [17-35]. The gate region can be functionalized so that current changes can be detected for a variety of gases, liquids, and biomolecules. Hydrogen sensors are particularly interesting for the emerging fuel cell vehicle market. There are also applications for detection of combustion gases for fuel leak detection in spacecraft, automobiles and aircraft, fire detectors, exhaust diagnosis and emissions from industrial processes [36-45]. A variety of gas, chemical and health-related sensors based on HEMT technology have been demonstrated with proper surface functionalization on the gate area of the HEMTs, including the detection of hydrogen, mercury ion, prostate specific antigen (PSA), DNA, and glucose [46-49].

Schottky diodes with Pt or Pd gates have been shown to be particularly effective hydrogen sensors. The sensing mechanism is ascribed to the dissociation of the molecular hydrogen on a catalytic metal gate contact, followed by diffusion of the atomic species to the semiconductor interface where it changes the piezoelectric charge in the channel and thus the effective barrier height on Schottky diode structures. This effect has been used in $\mathrm{Si}, \mathrm{SiC}, \mathrm{ZnO}$ and $\mathrm{GaN}$-based Schottky diode combustion gas sensors [50-59].

One of the main demands for such sensors is the ability to selectively detect hydrogen at room temperature in the presence of air. In addition, for most of these applications, the sensors should have very low power requirements and minimal weight. Nanostructures are natural candidates for this type of sensing. One important aspect is to increase their sensitivity for detecting gases such as hydrogen at low concentrations or temperatures, since typically an on-chip heater is used to increase the dissociation efficiency of molecular hydrogen to the atomic form and this adds complexity and power requirements. Previous work has shown that Pd-coated or doped carbon nanotubes (CNTs) become more sensitive to detection of hydrogen through catalytic dissociation of $\mathrm{H}_{2}$ to atomic hydrogen [60-62]. $\mathrm{ZnO}$ is also an attractive material for sensing applications and nanowires and nanorods in this system have been reported for $\mathrm{pH}$, gas, humidity and chemical sensing [63-66]. These nanostructures could also have novel applications in biomedical science because $\mathrm{ZnO}$ is bio-safe [67]. $\mathrm{ZnO}$ nanorods are relatively straightforward to synthesize by a number of different methods [67-80]. 
A couple of problems that arise when considering marketable applications are false alarms and stability. These can be caused by voltage swings in the device or simply by temperature changes altering the current level. A differential pair configuration of AlGaN/GaN HEMT diodes with a builtin control diode has been shown to reduce false alarms [81]. An additional key need for long-term monitoring applications is the availability of stable Ohmic contacts. We have found that boride-based Ohmic contacts on HEMTs show lower contact resistance than Ti/A1/Pt/Au after extended aging at $350{ }^{\circ} \mathrm{C}$ [82]. Our test system consists of an environmental chamber with an electrical feed-through for monitoring the device I-V characteristics. Mass flow controllers are used to introduce test gases and nitrogen to the chamber and vary the concentration, and the chamber passes through a furnace for testing at elevated temperature.

\section{Sensors for Hydrogen}

\subsection{ZnO Nanorods}

We have developed a consistent process for growing $\mathrm{ZnO}$ nanorods. We start by evaporating a thin Au layer $(20 \AA)$ and annealing to form islands, which serve as the nucleation sites for the nanorods. The nanorods are then deposited by Molecular Beam Epitaxy (MBE) using high purity Zn metal and an $\mathrm{O}_{3} / \mathrm{O}_{2}$ plasma discharge as the source chemicals. After $\sim 2 \mathrm{~h}$ growth time at $600{ }^{\circ} \mathrm{C}$, we have grown single-crystal nanorods with a typical length around $2 \sim 10 \mu \mathrm{m}$ and diameter in the range of 30-150 nm. Figure 1 shows a scanning electron micrograph of the as-grown rods. These alone are sensitive to hydrogen, but in some experiments we attempted to increase the sensitivity by sputtering $\mathrm{Pd}, \mathrm{Pt}, \mathrm{Au}$, $\mathrm{Ni}, \mathrm{Ag}$ or Ti thin films ( $\sim 100 \AA$ thick$)$ to form catalytic metal clusters.

Figure 1. SEM image of $\mathrm{ZnO}$ multiple nanorods.

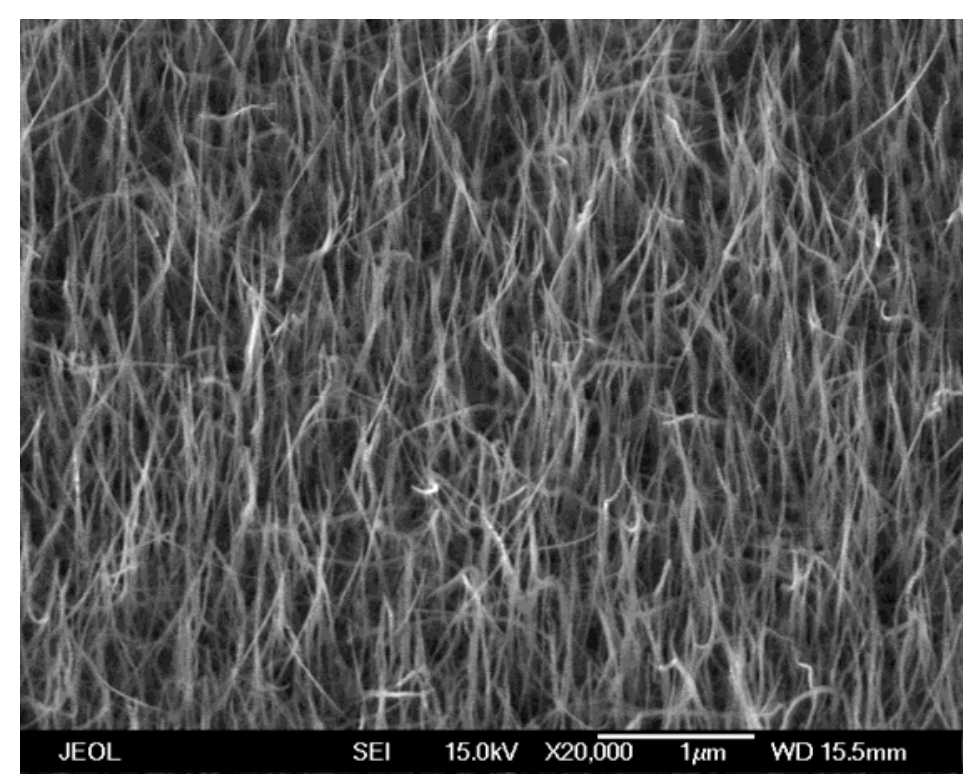

Contacts to the multiple nanorods were formed using a shadow mask and sputtering of $\mathrm{Al} / \mathrm{Ti} / \mathrm{Au}$ electrodes. The separation of the electrodes was $\sim 30 \mu \mathrm{m}$. Au wires were bonded to the contact pad for current-voltage (I-V) measurements performed at $25{ }^{\circ} \mathrm{C}$ in a range of different atmospheres $\left(\mathrm{N}_{2}, \mathrm{O}_{2}\right.$ or 
10-500 ppm $\mathrm{H}_{2}$ in $\mathrm{N}_{2}$ ). A schematic of the resulting sensor is shown in Figure 2 (top) with an optical image of a wire-bonded device shown below. Note that no currents were measured through the discontinuous $\mathrm{Au}$ islands and no thin film of $\mathrm{ZnO}$ on the sapphire substrate was observed with the growth condition for the nanorods. Therefore the measured currents are due to transport through the nanorods themselves. The I-V characteristics from the multiple nanorods were linear with typical currents of $0.8 \mathrm{~mA}$ at an applied bias of $0.5 \mathrm{~V}$.

Figure 2. Schematic of contact geometry for multiple nanorod gas sensor (top) and packaged, wire-bonded device for testing (bottom).
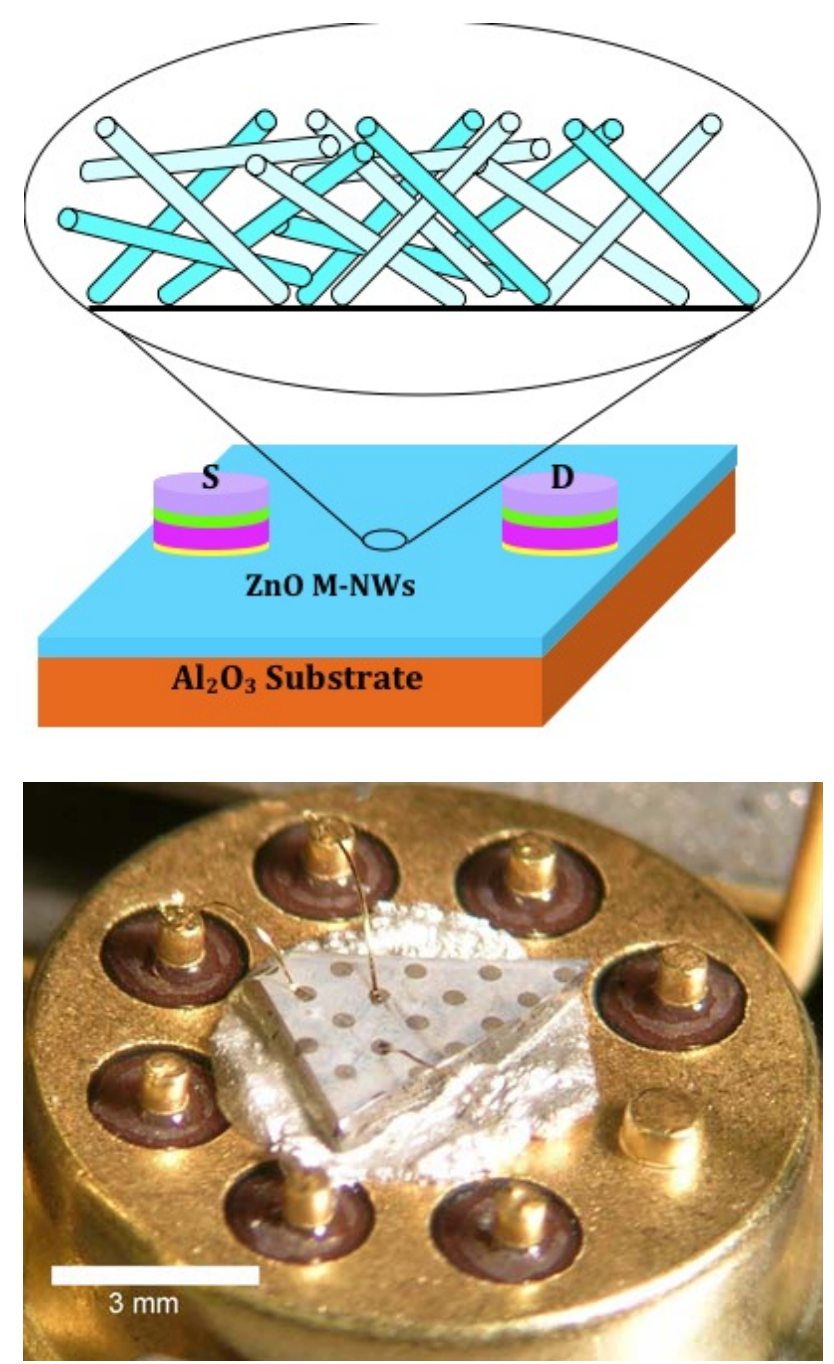

Figure 3 shows the time dependence of resistance of either Pt-coated or uncoated multiple $\mathrm{ZnO}$ nanorods as the gas ambient is switched from $\mathrm{N}_{2}$ to various concentrations of $\mathrm{H}_{2}$ in air (10-500 ppm) as time proceeds. There is clearly a strong increase (approximately a factor of 5) in the response of the Pd-coated nanorods to hydrogen relative to the uncoated devices. The addition of the Pd appears to be effective in catalytic dissociation of the $\mathrm{H}_{2}$ to atomic hydrogen. In addition, there was no response to the presence of $\mathrm{O}_{2}$ in the ambient at room temperature, and the relative response of Pt-coated nanorods is a function of $\mathrm{H}_{2}$ concentration in $\mathrm{N}_{2}$. The Pd-coated CNTs detected hydrogen down to $<10 \mathrm{ppm}$, with relative responses of $>2.6 \%$ at $10 \mathrm{ppm}$ and $>4.2 \%$ at $500 \mathrm{ppm}_{2}$ in $\mathrm{N}_{2}$ after 10 min exposure. 
By comparison, the uncoated devices showed relative resistance changes of $\sim 0.25 \%$ for $500 \mathrm{ppm}_{2}$ in $\mathrm{N}_{2}$ after 10 min exposure and the results were not consistent for lower concentrations. The gas sensing mechanism suggested include the desorption of adsorbed surface hydrogen and grain boundaries in poly- $\mathrm{ZnO}$ [83], exchange of charges between adsorbed gas species and the $\mathrm{ZnO}$ surface leading to changes in depletion depth [84] and changes in surface or grain boundary conduction by gas adsorption/desorption [85]. It should be noted that hydrogen introduces a shallow donor state in $\mathrm{ZnO}$ and this change in near-surface conductivity may also play a role.

Figure 3. Time dependence of resistance of either Pd-coated or uncoated multiple $\mathrm{ZnO}$ nanorods as the gas ambient is switched from $\mathrm{N}_{2}$ to various concentrations of $\mathrm{H}_{2}$ in air (10-500 ppm).

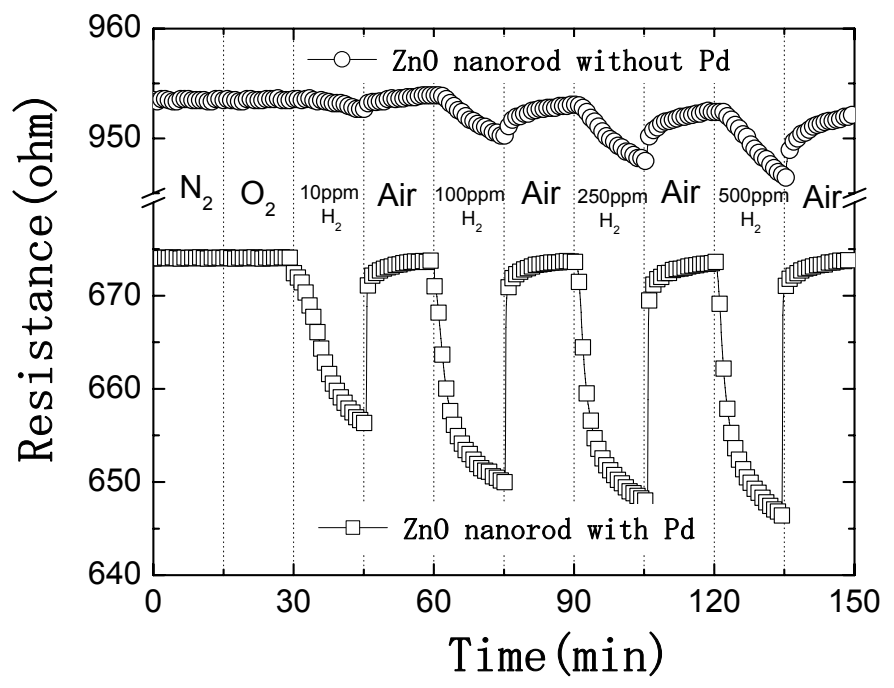

Figure 4 shows the time dependence of resistance change of Pt-coated multiple $\mathrm{ZnO}$ nanorods as the gas ambient is switched from vacuum to $\mathrm{N}_{2}$, oxygen or various concentrations of $\mathrm{H}_{2}$ in air (10$500 \mathrm{ppm}$ ) and then back to air. This data confirms the absence of sensitivity to $\mathrm{O}_{2}$. The resistance change during the exposure to hydrogen was slower in the beginning and the rate resistance change reached a maximum at $1.5 \mathrm{~min}$ of the exposure time. This could be due to the some of the Pd becoming covered with native oxide and then removed by exposure to hydrogen. Since the available surface Pd for catalytic chemical absorption of hydrogen increased after the removal of oxide, the rate of resistance change increased. However, the Pd surface gradually saturated with the hydrogen and resistance change rate decreased. When the gas ambient switched from hydrogen to air, the oxygen reacted with hydrogen right away, and the resistance of the nanorods changed back to the original value instantly.

Figure 5 shows the Arrhenius plot of the rate of nanorod resistance change. The rate of resistance change for the nanorods exposed to the $500 \mathrm{ppm} \mathrm{H}_{2}$ in $\mathrm{N}_{2}$ was measured at the different temperatures. An activation energy of $12 \mathrm{~kJ} /$ mole was extracted from the slope of the Arrehnius plot. This value is larger than that of the typical diffusion process. Therefore the dominant mechanism for this sensing process should be the chemisorption of hydrogen to the Pd surface. 
Figure 4. Relative response of Pd-coated nanorods as a function of $\mathrm{H}_{2}$ concentration in $\mathrm{N}_{2}$.

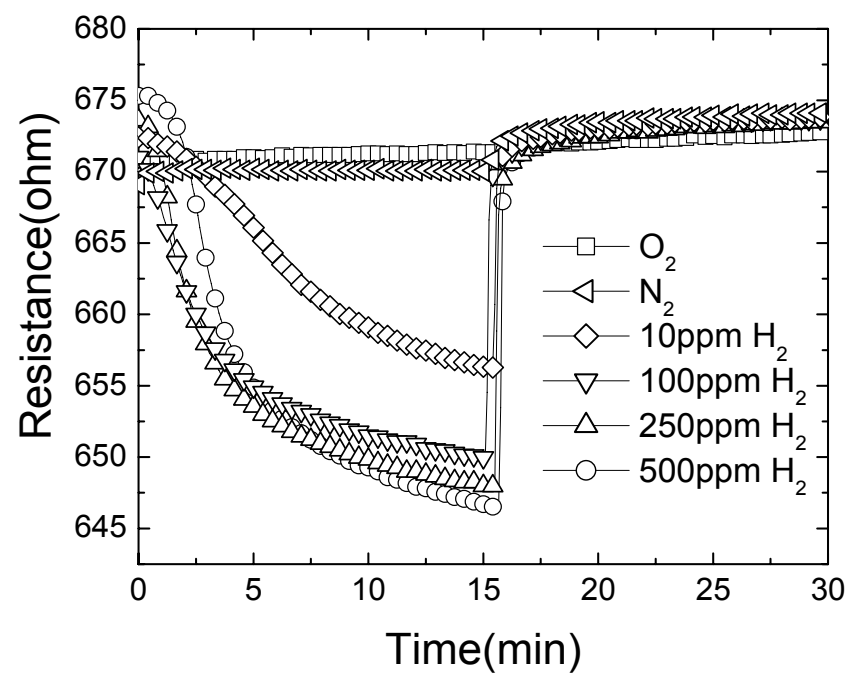

Figure 5. Time dependence of resistance change of Pd-coated multiple $\mathrm{ZnO}$ nanorods as the gas ambient is switched from $\mathrm{N}_{2}$ to oxygen or various concentrations of $\mathrm{H}_{2}$ in air (10-500 ppm) and then back to $\mathrm{N}_{2}$.

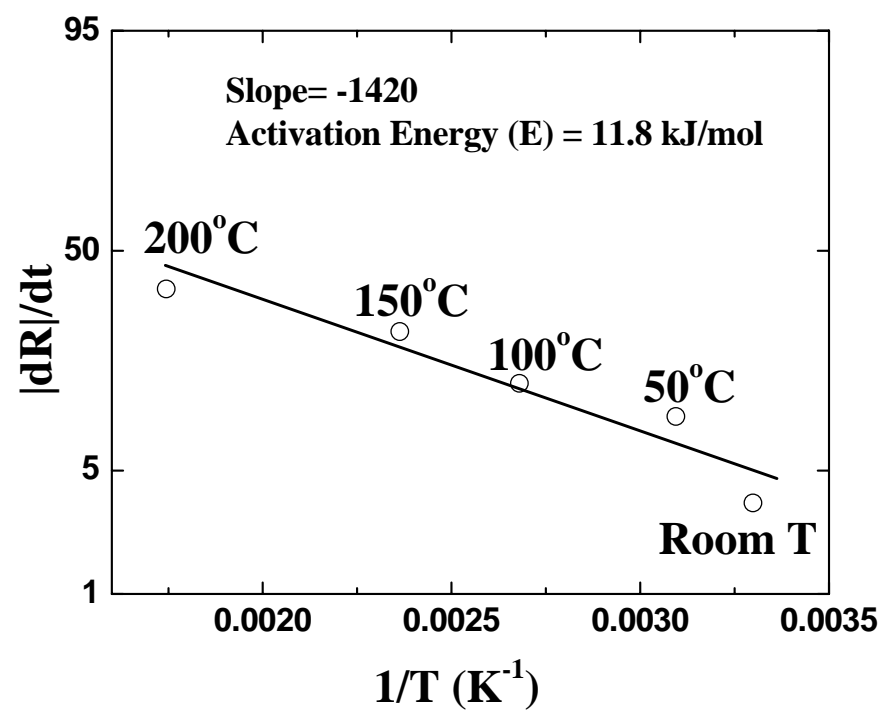

Having established improved sensitivity by coating the nanorods with catalytic metal, we then investigated the effects of different metals to further improve sensitivity and response. Using the same coating procedure described above, we investigated metal coatings of $\mathrm{Ti}, \mathrm{Ni}, \mathrm{Ag}, \mathrm{Au}, \mathrm{Pt}$, and $\mathrm{Pd}$. Figure 6 shows the time dependence of relative resistance change of either metal-coated or uncoated multiple $\mathrm{ZnO}$ nanorods as the gas ambient is switched from air to $500 \mathrm{ppm}$ of $\mathrm{H}_{2}$ in $\mathrm{N}_{2}$. These were measured at a bias voltage of $0.5 \mathrm{~V}$. There is a strong enhancement in response with $\mathrm{Pd}$, and to a lesser extent Pt coatings, but the other metals produce little or no change. This is consistent with the known catalytic properties of these metals for hydrogen dissociation. Pd has a higher permeability than Pt but the solubility of $\mathrm{H}_{2}$ is larger in the former [86]. Moreover, studies of the bonding of $\mathrm{H}$ to $\mathrm{Ni}, \mathrm{Pd}$ and $\mathrm{Pt}$ surfaces have shown that the adsorption energy is lowest on Pt [87]. 
Figure 6. Time dependence of relative resistance response of metal-coated multiple $\mathrm{ZnO}$ nanorods as the gas ambient is switched from $\mathrm{N}_{2}$ to $500 \mathrm{ppm}$ of $\mathrm{H}_{2}$ in air as time proceeds. There was no response to $\mathrm{O}_{2}$.

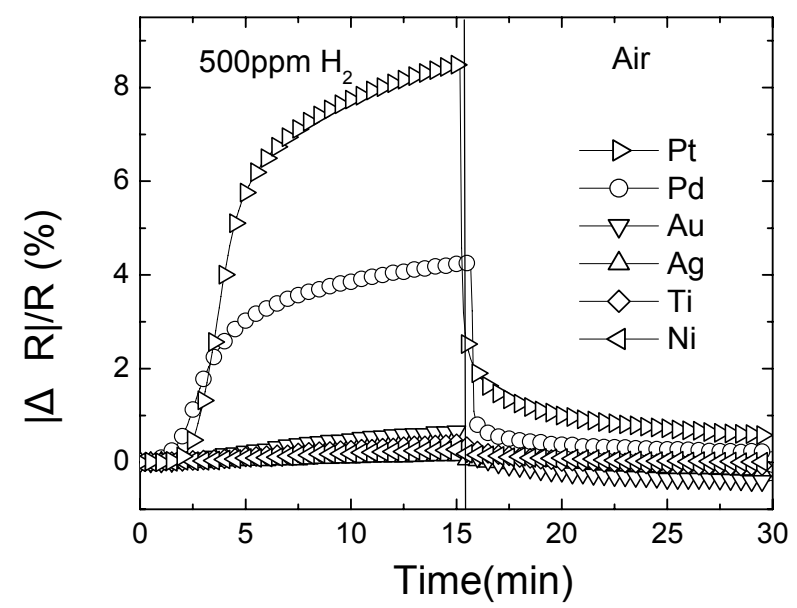

The power requirements for the sensors were very low, which is a key requirement for a competitive marketable sensor. Figure 7 shows the I-V characteristics measured at $25{ }^{\circ} \mathrm{C}$ in both a pure $\mathrm{N}_{2}$ ambient and after $15 \mathrm{~min}$ in a $500 \mathrm{ppm} \mathrm{H}_{2}$ in $\mathrm{N}_{2}$ ambient. Under these conditions, the resistance response is $8 \%$ and is achieved for a power requirement of only $0.4 \mathrm{~mW}$. This compares well with competing technologies for hydrogen detection such as Pd-loaded carbon nanotubes [60,61].

Figure 7. $\mathrm{I}-\mathrm{V}$ characteristic of Pt-coated nanowires in air and after $15 \mathrm{mins}$ in $500 \mathrm{ppm} \mathrm{H}_{2}$ in air.

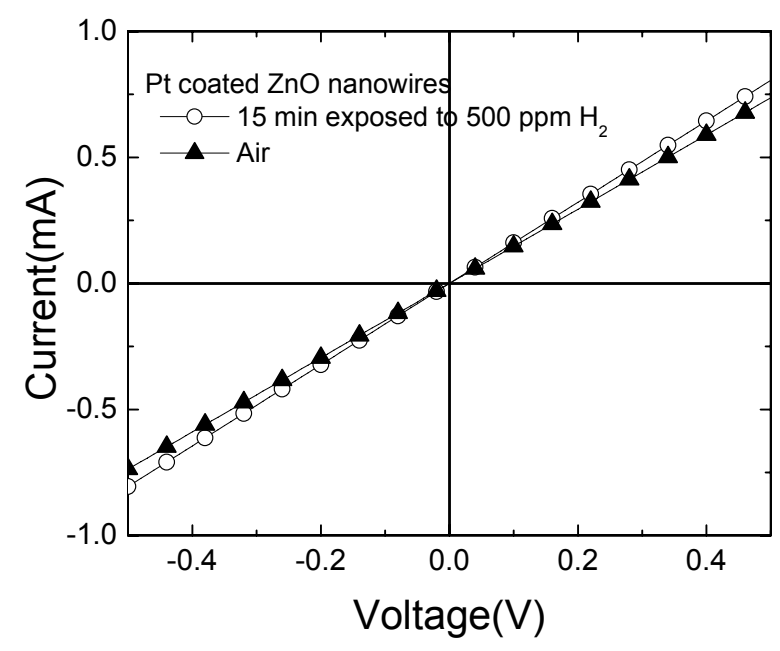

\subsection{AlGaN/GaN HEMT}

The device layer structures were grown on C-plane $\mathrm{Al}_{2} \mathrm{O}_{3}$ substrates by Metal Organic Chemical Vapor Deposition (MOCVD). The layer structure included an initial $2 \mu \mathrm{m}$ thick undoped GaN buffer followed by a $35 \mathrm{~nm}$ thick unintentionally doped $\mathrm{Al}_{0.28} \mathrm{Ga}_{0.72} \mathrm{~N}$ layer. Mesa isolation was achieved by using an inductively coupled plasma system with $\mathrm{Ar} / \mathrm{Cl}_{2}$ based discharges. The Ohmic contacts were 
formed by lift-off of sputtered $\mathrm{Ti} / \mathrm{Al} / \mathrm{TiB}_{2} / \mathrm{Ti} / \mathrm{Au}$, followed by annealing at $850{ }^{\circ} \mathrm{C}$ for $45 \mathrm{sec}$ under a flowing $\mathrm{N}_{2}$ ambient. A thin (100 $\AA$ ) Pt Schottky contact was deposited by e-beam evaporation for the Schottky metal. The final step was deposition of e-beam evaporated Ti/Au interconnection contacts. The individual devices were diced and wire-bonded to carriers. These were then placed in our test chamber. Figure 8 shows a schematic of the completed devices and an optical image of a wire bonded device. Mass flow controllers were used to control the gas flow through the chamber, and the devices were exposed to either $100 \%$ pure $\mathrm{N}_{2}$, or $\mathrm{H}_{2}$ concentrations of $500 \mathrm{ppm}$ down to $1 \mathrm{ppm}$ in $\mathrm{N}_{2}$ and temperatures from 25 to $500{ }^{\circ} \mathrm{C}$.

Figure 8. Cross-sectional schematic of completed MOS diode on AlGaN/GaN HEMT layer structure (left) and plan-view photograph of device(right).
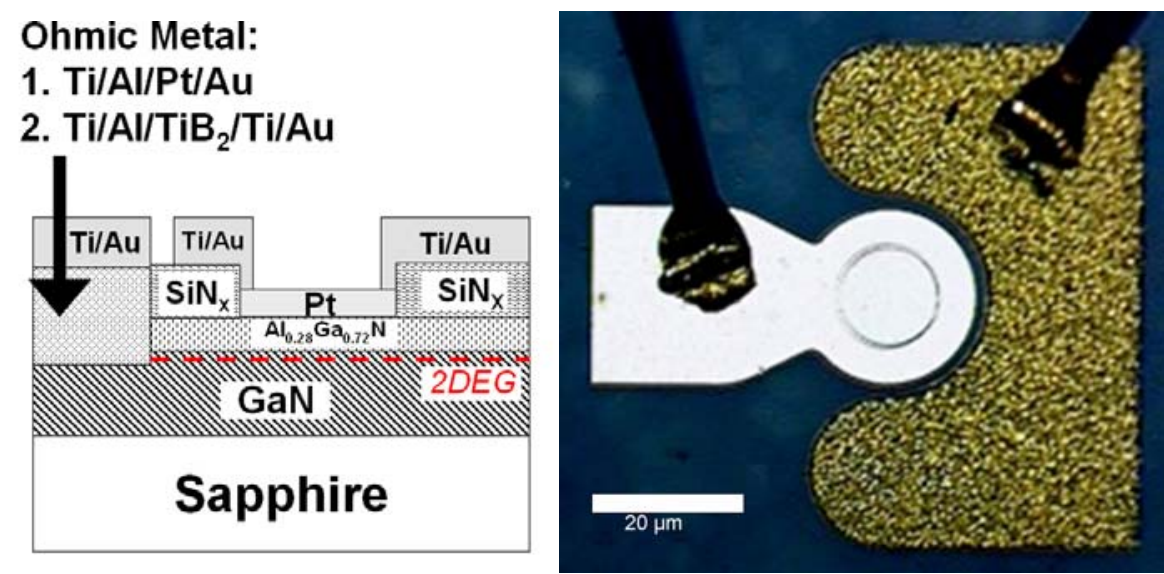

Figure 9 shows the linear (top) and log scale (bottom) forward current-voltage (I-V) characteristics at $25{ }^{\circ} \mathrm{C}$ of the HEMT diode, both in air and in a $1 \% \mathrm{H}_{2}$ in air atmosphere. For these diodes, the current increases upon introduction of the $\mathrm{H}_{2}$, through a lowering of the effective barrier height. The $\mathrm{H}_{2}$ catalytically decomposes on the Pt metallization and diffuses rapidly to the interface where it forms a dipole layer. The differential change in forward current upon introduction of the hydrogen into the ambient is $\sim 1 \mathrm{~mA}$ over the voltage range examined.

Figure 9. I-V characteristics in linear (top) or log (bottom) form of Pt-gated diode measured in air or $1 \%$ hydrogen ambient at $25^{\circ} \mathrm{C}$.
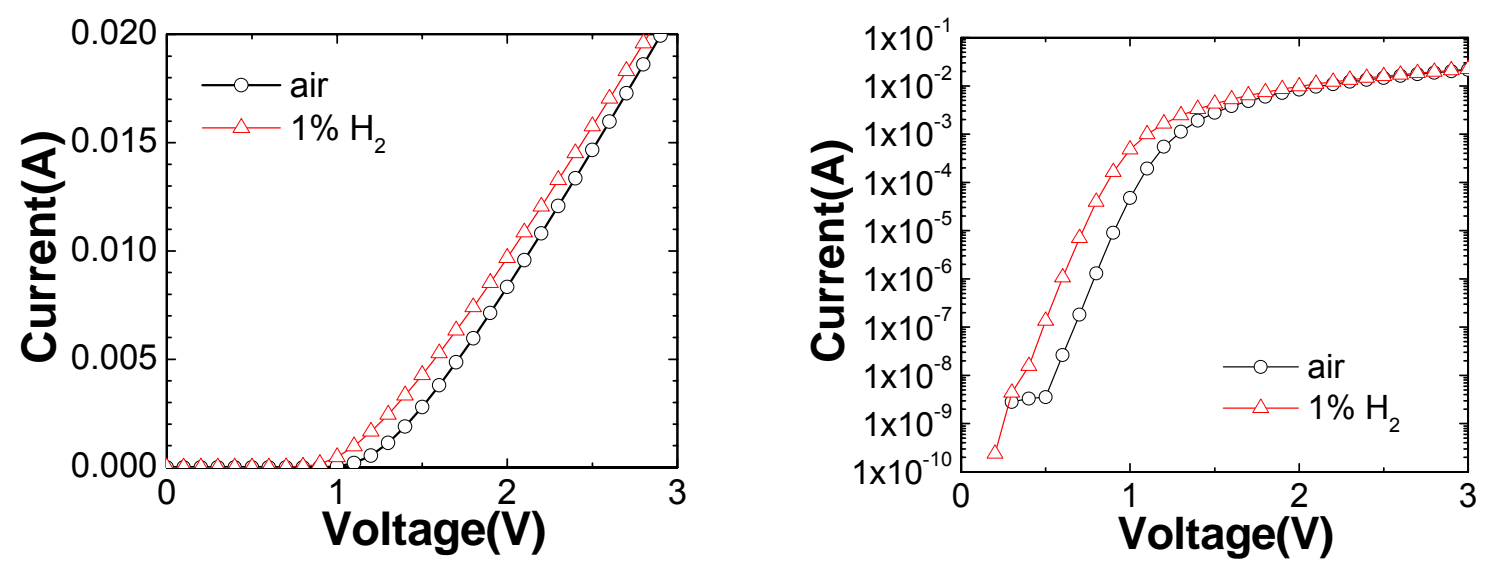
To test the time response of the sensors, a $10 \% \mathrm{H}_{2} / 90 \% \mathrm{~N}_{2}$ ambient was switched into the chamber through a mass flow controller for periods of 10,20 or 30 seconds and then switched back to pure $\mathrm{N}_{2}$. Figure 10 shows the time dependence of forward current at a fixed bias of $2 \mathrm{~V}$ under these conditions. The response of the sensor is rapid $(<1 \mathrm{sec})$, with saturation taking almost the full 30 seconds. Upon switching out of the hydrogen-containing ambient, the forward current decays exponentially back to its initial value. This time constant is determined by the volume of the test chamber and the flow rate of the input gases and is not limited by the response of the diode itself.

Figure 10. Time response at $25{ }^{\circ} \mathrm{C}$ of MOS-HEMT based diode forward current at a fixed bias of $2 \mathrm{~V}$ when switching the ambient from $\mathrm{N}_{2}$ to $10 \% \mathrm{H}_{2} / 90 \% \mathrm{~N}_{2}$ for periods of 10,20 or $30 \mathrm{sec}$ and then back to pure $\mathrm{N}_{2}$.

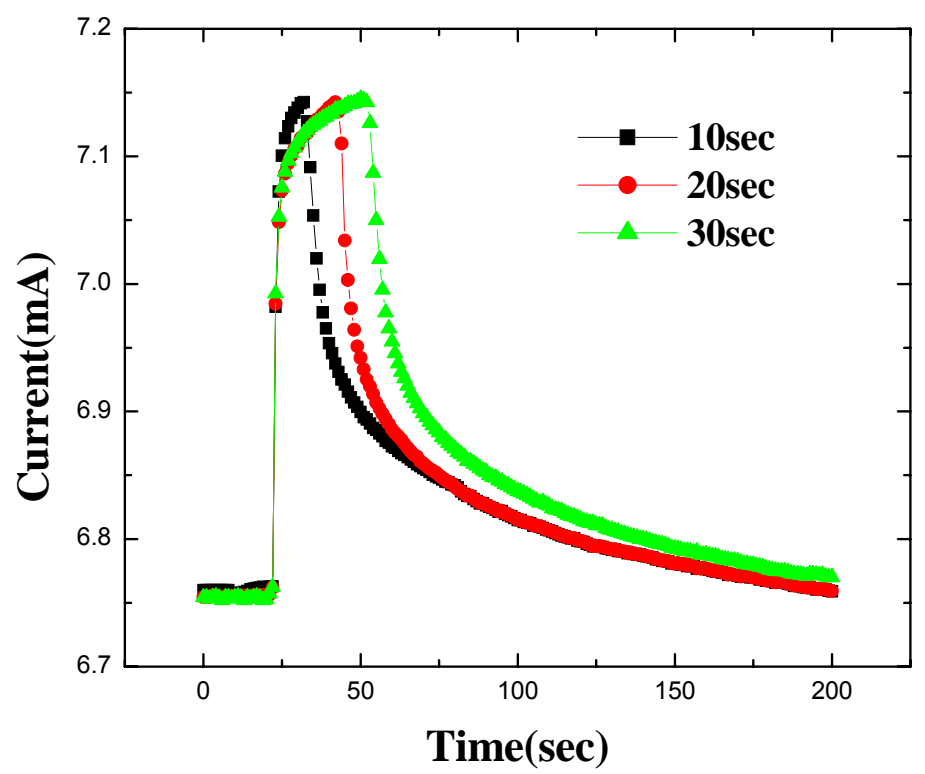

To further study response and detection limits, devices were tested under both forward and reverse bias conditions at room temperature $\left(25^{\circ} \mathrm{C}\right)$ in a nitrogen atmosphere at hydrogen concentrations ranging from 500 to $5 \mathrm{ppm}$, controlled by diluting the gas mix with nitrogen using mass flow controllers. There was again an increase in current under both forward and reverse bias conditions upon exposure to hydrogen, as shown in Figure 11. This is consistent with previously discussed mechanisms in which the hydrogen molecules dissociate into hydrogen atoms through the catalytic action of the Pt gate contact, and diffuse to the Pt/AlGaN interface $[88,89]$. The hydrogen atoms form a dipole layer, lower the Schottky barrier height, and increase net positive charges on the AlGaN surface as well as negative charges in the $2 \mathrm{DEG}$ channel. The calculated barrier height decrease for $500 \mathrm{ppm}$ and $100 \mathrm{ppm}$ hydrogen is $5 \mathrm{meV}$ and $1 \mathrm{meV}$, respectively. The ideality factors were calculated to be 1.25 and 1.23 in 500 and 100 ppm hydrogen, respectively, compared to 1.26 in $100 \%$ nitrogen. 
Figure 11. Forward and reverse bias plot of diode current in varying atmospheres.

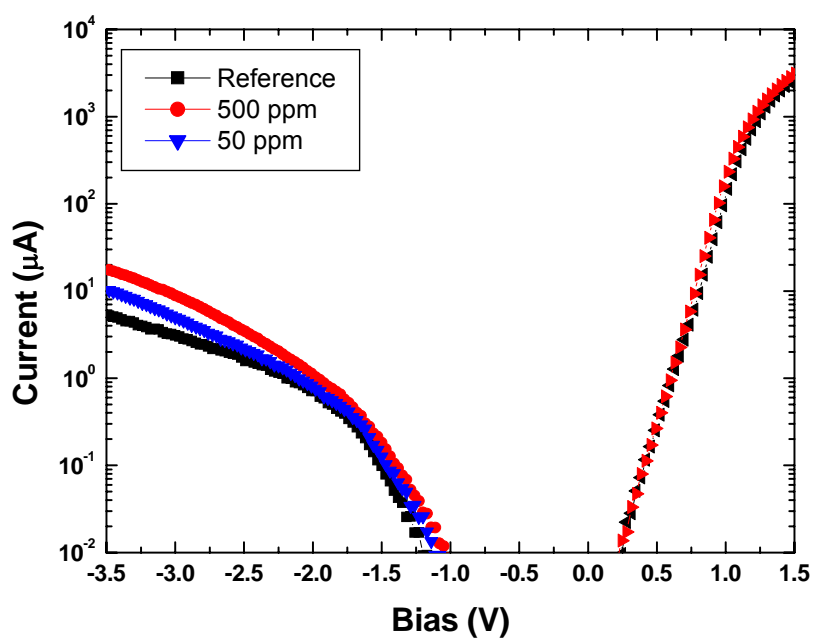

However, a plot of hydrogen sensitivity (defined as the drain current change over the initial drain current) versus bias voltage shows different characteristics for forward and reverse bias polarity conditions at $500 \mathrm{ppm}$ of $\mathrm{H}_{2}$, as shown in Figure 12. For the forward bias condition, there is a maximum sensitivity obtained around $1 \mathrm{~V}$ and further increase of bias voltage reduces the sensitivity. The sensitivity for the reverse bias condition is quite different and it increases proportionally to the bias voltage. We have proposed the following mechanism for the change in sensitivity under forward and reverse bias conditions: (1) The initial increase in the sensitivity is due to the Schottky barrier height reduction. (2) Further increase in forward bias allows electrons to flow across the Schottky barrier. These excess electrons bind with $\mathrm{H}^{+}$, form atomic hydrogen, and gradually destroy the dipole layer at the interface, therefore losing the hydrogen detection sensitivity. (3) For the reverse bias condition, electrons given away by the hydrogen atom may be swept across the depletion region. At higher reverse bias voltage, a higher driving force is applied to the electrons to move across the depletion region. Thus the dipole layer is amplified at the $\mathrm{Pt} / \mathrm{AlGaN}$ interface for higher reverse bias voltage. Due to this dipole layer amplification, the detection sensitivity is enhanced at higher reverse bias voltage.

The detection sensitivity as a function of hydrogen concentration is shown in Figure 13. It is clear that the diodes are much more sensitive under reverse bias conditions. A detection limit of $100 \mathrm{ppm}$ is achieved under forward bias, but the reverse bias detection limit is an order of magnitude lower, 10 ppm. The change in current at $10 \mathrm{ppm}$ is $14 \%$ and over $200 \%$ at $500 \mathrm{ppm}$ under reverse bias conditions, where forward bias operation results in changes of $25-75 \%$ over the $100-500 \mathrm{ppm}$ range. This is consistent with published reports indicating improved sensitivity under reverse bias [90]. The reliability of the hydrogen sensor may be quite different under the two bias voltage polarities, since different degradation mechanisms in GaN devices are accelerated by either the presence of high voltage depletion regions (reverse bias) or current injection (forward bias) [91]. 
Figure 12. Percentage change in current as a function of bias at $500 \mathrm{ppm} \mathrm{H}_{2}$.

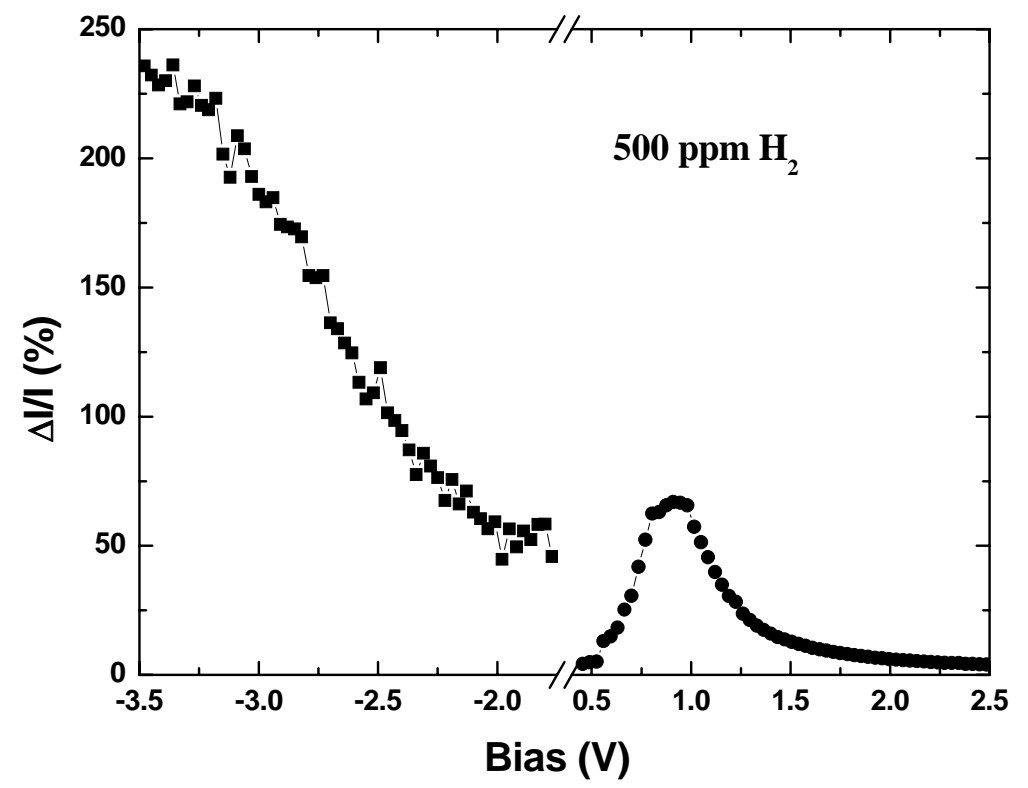

Figure 13. Percentage change in current as a function of hydrogen concentration under both forward and reverse bias.

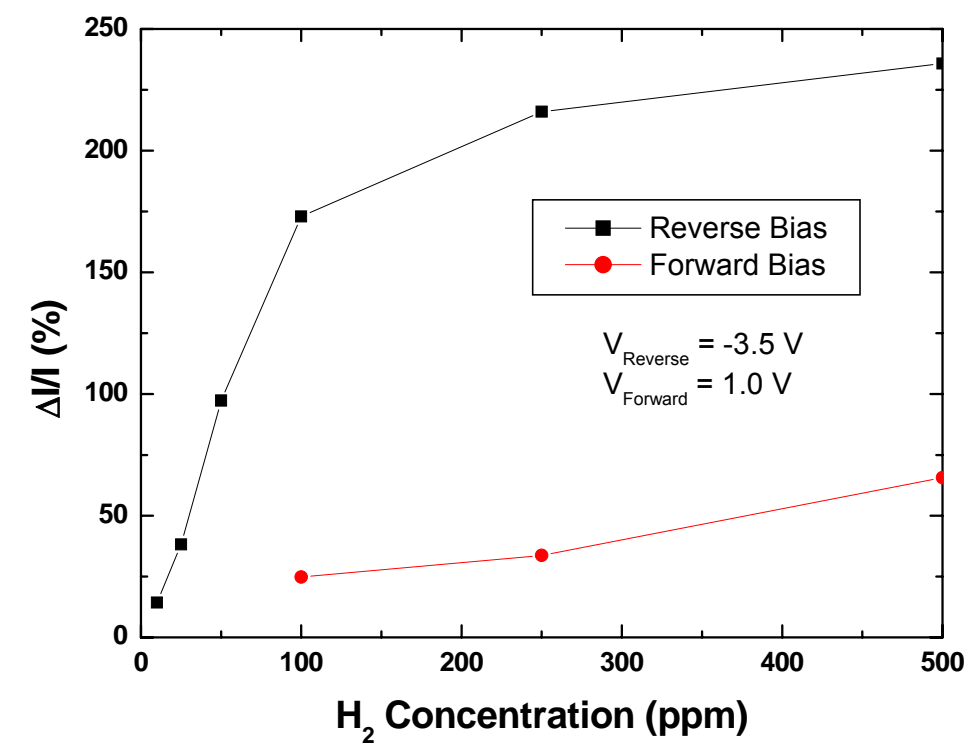

\section{Sensors for $\mathrm{CO}_{2}$}

A sensor for $\mathrm{CO}_{2}$ gas has many potential applications, for example monitoring global warming, indoor air quality control, process control in fermentation, and the medical field [92-95]. A particular application that we have focused on is quantification of $\mathrm{CO}_{2}$ concentrations in patient's exhaled breath. This is a critically important measurement that allows health care providers to assess adequacy of ventilation and circulation in subjects. The most common approach for $\mathrm{CO}_{2}$ detection is based on nondispersive infrared (NDIR) sensors, which are the simplest of the spectroscopic sensors [96-99]. The best detection limits for the NDIR sensors in the range 20-10,000 ppm. The key components of NDIR 
sensors are an infrared source, a light tube, an interference filter, and an infrared detector, thus the technology is quite limited by physical size and power consumption. In recent years, monomers or polymers containing an amino-group, such as tetrakis (hydroxyethyl)ethylenediamine, tetraethylenepentamine and polyethyleneimine (PEI) have been used as coatings of surface acoustic wave transducers to overcome these limitations [100-104]. PEI has also been used as a coating on carbon nanotubes for $\mathrm{CO}_{2}$ sensing by measuring the conductivity of nanotubes upon exposure to $\mathrm{CO}_{2}$ [105-108].

In this section, we report the design and fabrication of a chemically functionalized $\mathrm{AlGaN} / \mathrm{GaN}$ HEMT device for $\mathrm{CO}_{2}$ sensing. Specific sensitivity can be achieved by employing a $\mathrm{CO}_{2}$ recognition layer of $\mathrm{PEI} / \mathrm{starch}$ on the gate area of the HEMT. The effect of temperature and $\mathrm{CO}_{2}$ concentration on the sensing sensitivity was investigated.

The device fabrication followed the standard procedure outlined previously. In this case the HEMT structure consisted of an undoped $\mathrm{GaN}$ buffer, a thin undoped $\mathrm{Al}_{0.3} \mathrm{Ga}_{0.7} \mathrm{~N}$ spacer, and a Si-doped $\mathrm{Al}_{0.3} \mathrm{Ga}_{0.7} \mathrm{~N}$ cap layer. The epi-layers were grown by Metal-Organic Chemical Vapor Deposition (MOCVD) on silicon (111) substrates. Mesa isolation was again achieved by ICP etching, ohmic contacts were formed using annealed $\mathrm{Ti} / \mathrm{Al} / \mathrm{Pt} / \mathrm{Au}$, interconnects formed using $\mathrm{Ti} / \mathrm{Au}$ metallization, and the gate was left open for this experiment. Polymethyl methacrylate (PMMA) was used to encapsulate the sample, with only the gate region opened for selective functionalization using e-beam lithography. A mixture of PEI and starch was used for the $\mathrm{CO}_{2}$-sensitive layer and the mixture was applied via spincoating. The completed device was then diced, wire-bonded, and mounted on the previously described test apparatus. A plan view photomicrograph of a completed device and a schematic cross-section of the device are shown in Figure 14. The gas exposure sequence in this case consisted of repeated exposures to gas with different $\mathrm{CO}_{2}$ concentration balanced with pure $\mathrm{N}_{2}$.

Figure 14. (a) Schematic of $\mathrm{AlGaN} / \mathrm{GaN}$ HEMT based $\mathrm{CO}_{2}$ sensor (b) plan view photomicrograph of $\mathrm{PEI} /$ starch functionalized $\mathrm{HEMT} \mathrm{CO}_{2}$ sensor.

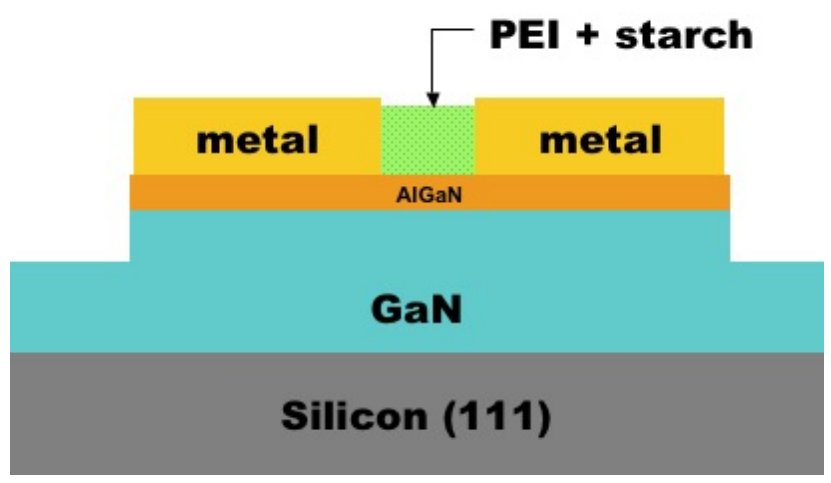

(a)

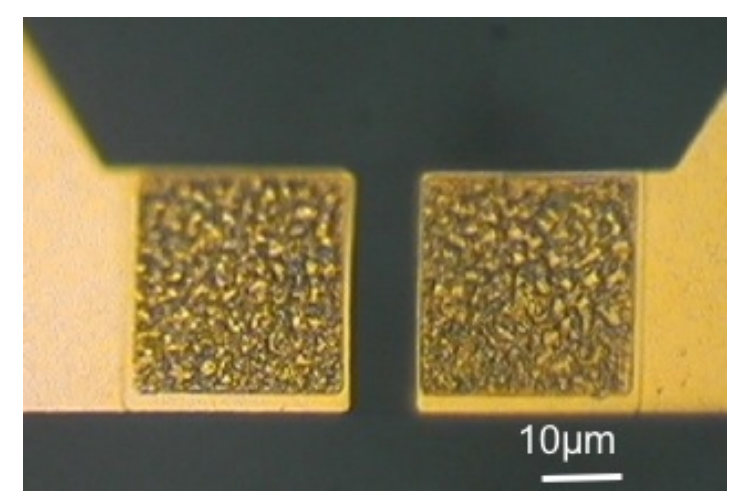

(b)

The interaction between $\mathrm{CO}_{2}$ and amino group-containing compounds with the influence of water molecules is based on an acid-base reaction. The purpose of adding starch into the PEI in our experiment was to enhance the absorption of the water molecules into the PEI/starch thin film. Several possible reaction mechanisms have been suggested. The key reaction was that primary amine groups, 
$-\mathrm{NH}_{2}$, on the PEI main chain reacted with $\mathrm{CO}_{2}$ and water forming $-\mathrm{NH}_{3}{ }^{+}$ions and the $\mathrm{CO}_{2}$ molecule became OCOOH ions, changing the polarity of the PEI main chain. This will then affect the surface charge on the gate region of the HEMT, thus changing the carrier density in the 2DEG, effectively modulating the source-drain current in the same way that a real gate would. Figure 15 shows the drain current of PEI/starch functionalized HEMT sensors measured exposed to different $\mathrm{CO}_{2}$ concentration ambients.

Figure 15. Drain current of PEI/starch functionalized HEMT sensor measured at fixed source-drain during the exposure to different $\mathrm{CO}_{2}$ concentration ambients. The drain bias voltage was $0.5 \mathrm{~V}$ and measurements were conducted at $108{ }^{\circ} \mathrm{C}$.

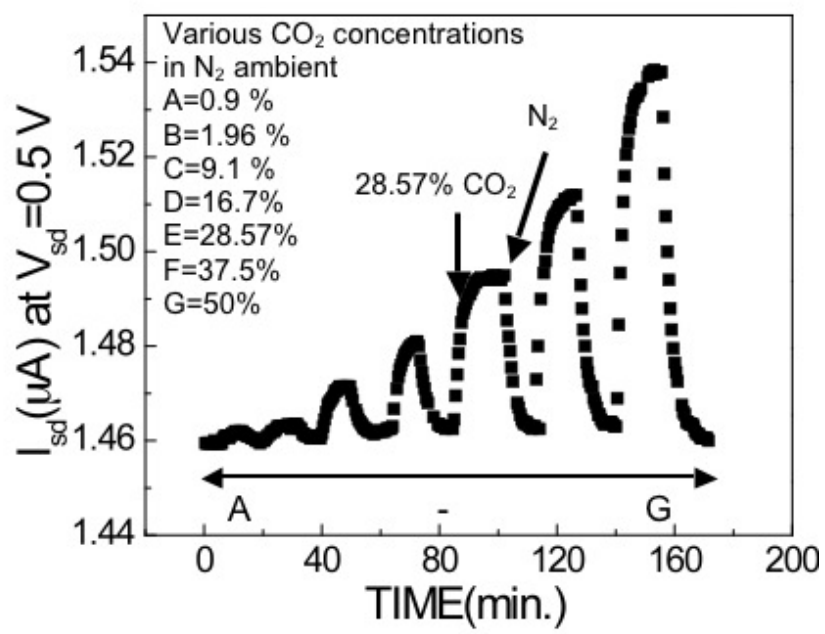

The measurements were conducted at $108{ }^{\circ} \mathrm{C}$ and a fixed source-drain bias voltage of $0.5 \mathrm{~V}$. The reason for choosing this temperature will be discussed later. The current increased with the introduction of $\mathrm{CO}_{2}$ gas due to the increase in net positive charge on the gate area, which induced electrons in the 2DEG channel. The response to $\mathrm{CO}_{2}$ gas has a wide dynamic range from $0.9 \%$ to $50 \%$. Higher $\mathrm{CO}_{2}$ concentrations were not tested because there is little interest in these for medical related applications. The response times were on the order of 100 seconds. The signal decay time was slower than the rise time and was due to the longer time required to purge $\mathrm{CO}_{2}$ out from the test chamber.

The ambient temperature is critical to the sensitivity of this device. Figure 16 shows the percentage of drain current change as a function of $\mathrm{CO}_{2}$ concentration from 0.9 to $40 \%$ at five different testing temperatures ranging from 46 to $220{ }^{\circ} \mathrm{C}$. The insert of the figure shows an enlargement of the drain current changes at lower concentrations. The drain current changes increased monotonically to the $\mathrm{CO}_{2}$ concentration for all the tested temperatures. However, the HEMT sensors showed greater sensitivity at the higher testing temperatures. There is a particularly noticeable increase in sensitivity from the sensors tested at $61{ }^{\circ} \mathrm{C}$ to those tested at $108^{\circ} \mathrm{C}$. This difference is likely due to an increase in the reaction rate between amine groups and $\mathrm{CO}_{2}$ as well as the diffusion of $\mathrm{CO}_{2}$ molecules into the PEI thin film. Another important figure of merit for sensors is the reversibility and reproducibility, shown in Figure 17. The sensor was exposed to two different $\mathrm{CO}_{2}$ concentrations twice at 28.5 and $37.5 \%$, respectively. Similar responses were obtained for the same $\mathrm{CO}_{2}$ concentration for both cases, and the current recovered back to the baseline level easily in $\mathrm{N}_{2}$. 
Figure 16. The drain current changes of HEMT sensor as a function of $\mathrm{CO}_{2}$ concentration. The inset is the current change of the sensors as function of lower $\mathrm{CO}_{2}$ concentrations $(0.9$ $10 \%)$.

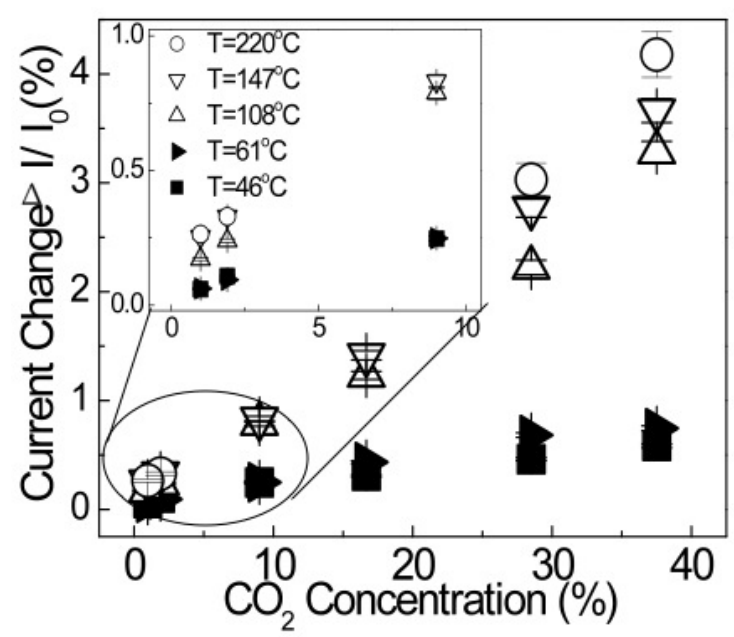

Figure 17. Drain current of PEI/starch functionalized HEMT sensor as a function of time measured at a drain bias voltage of $0.5 \mathrm{~V}$ and at $108^{\circ} \mathrm{C}$.

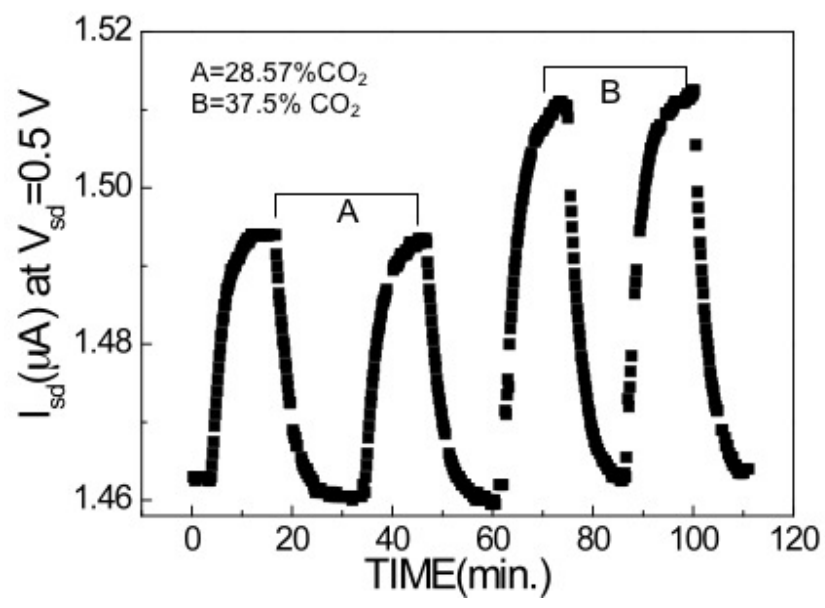

\section{Sensors for Ethylene}

Ethylene is a particularly interesting case for gas sensors because the strong double bonds prove difficult to dissociate on a catalytic surface at modest temperatures. This is where the high temperature capabilities of wide bandgap materials become very relevant. In this section we will report on detection of $\mathrm{C}_{2} \mathrm{H}_{4}$ using bulk $\mathrm{ZnO}$ schottky diodes and AlGaN/GaN MOS-diodes, with reasonable sensitivity demonstrated above $150{ }^{\circ} \mathrm{C}$.

\subsection{Bulk $\mathrm{ZnO}$}

The bulk $\mathrm{ZnO}$ crystals from Cermet, Inc. showed electron concentration of $9 \times 10^{16} \mathrm{~cm}^{-3}$ and an electron mobility of $200 \mathrm{~cm}^{2} / \mathrm{V}$ s. at room temperature from van der Pauw measurements. Ohmic contacts were formed on the back (O-face) of the substrates by depositing full area $\mathrm{Ti} / \mathrm{Al} / \mathrm{Pt} / \mathrm{Au}$ by ebeam evaporation followed by annealing at $200{ }^{\circ} \mathrm{C}$ for $1 \mathrm{~min}$ in $\mathrm{N}_{2}$ ambient. The front face was coated 
with plasma-enhanced chemical vapor deposited $\mathrm{SiN}_{\mathrm{X}}$ at $100^{\circ} \mathrm{C}$ and windows opened by wet etching so that a thin $(20 \mathrm{~nm})$ layer of Pt could be deposited by e-beam evaporation to serve as the sensing metal. The final $\mathrm{Ti} / \mathrm{Au}$ interconnect contacts were deposited, followed by dicing, wire-bonding, and mounting to the test apparatus. Figure 18 shows a schematic of the completed device.

Figure 18. Schematic of $\mathrm{AlGaN} / \mathrm{GaN}$ MOS diode (top) and bulk $\mathrm{ZnO}$ Schottky diode structure (bottom).

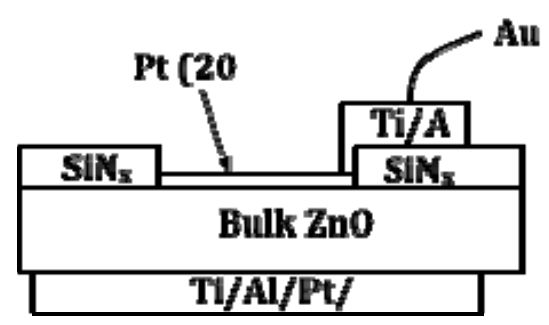

Figure 19 shows the $\mathrm{I}-\mathrm{V}$ characteristics at 50 and $150{ }^{\circ} \mathrm{C}$ of the $\mathrm{Pt} / \mathrm{ZnO}$ diode both in pure $\mathrm{N}_{2}$ and in ambients containing various concentrations of $\mathrm{C}_{2} \mathrm{H}_{4}$. At a given forward or reverse bias, the current increases upon introduction of the $\mathrm{C}_{2} \mathrm{H}_{4}$, through a lowering of the effective barrier height. The sensing mechanism is once again the decomposition of the $\mathrm{C}_{2} \mathrm{H}_{4}$ on the catalytic Pt surface, followed by diffusion to the underlying interface with the $\mathrm{ZnO}$. As in hydrogen sensors, the atomic hydrogen forms an interfacial dipole layer that will reduce the Schottky barrier height, which will be manifested by a change in the DC I-V characteristics of the diode. The recovery was many orders of magnitude longer than for $\mathrm{Pt} / \mathrm{GaN}$ diodes measured under the same conditions in the same chamber, suggesting that hydrogen diffuses into the $\mathrm{ZnO}$ lattice much more than it does for GaN. The changes in current at fixed bias or bias at fixed current were larger for the $\mathrm{ZnO}$ diodes than for AlGaN/GaN MOS diodes, which will be discussed in the next section, because of this additional detection mechanism, as shown in Figure 20. Note that the changes in these parameters are approximately an order of magnitude larger at $150{ }^{\circ} \mathrm{C}$, suggesting that testing at even higher temperature will further improve sensitivity, but the $\mathrm{ZnO}$ diodes were not thermally stable above $\sim 300^{\circ} \mathrm{C}$.

Figure 19. $\mathrm{I}-\mathrm{V}$ characteristics at $50{ }^{\circ} \mathrm{C}$ (top) or $150{ }^{\circ} \mathrm{C}$ (bottom) of $\mathrm{Pt} / \mathrm{ZnO}$ diodes measured in different ambients.

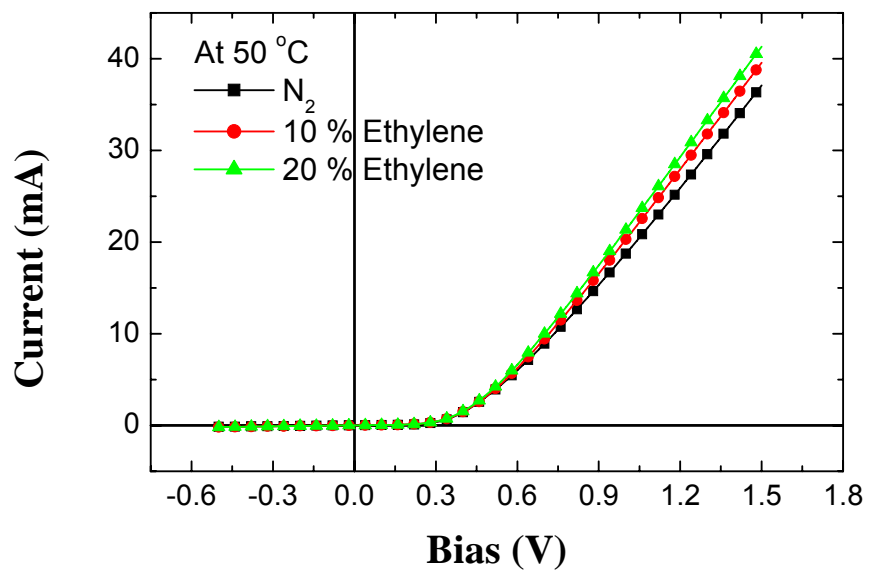


Figure 19. Cont.

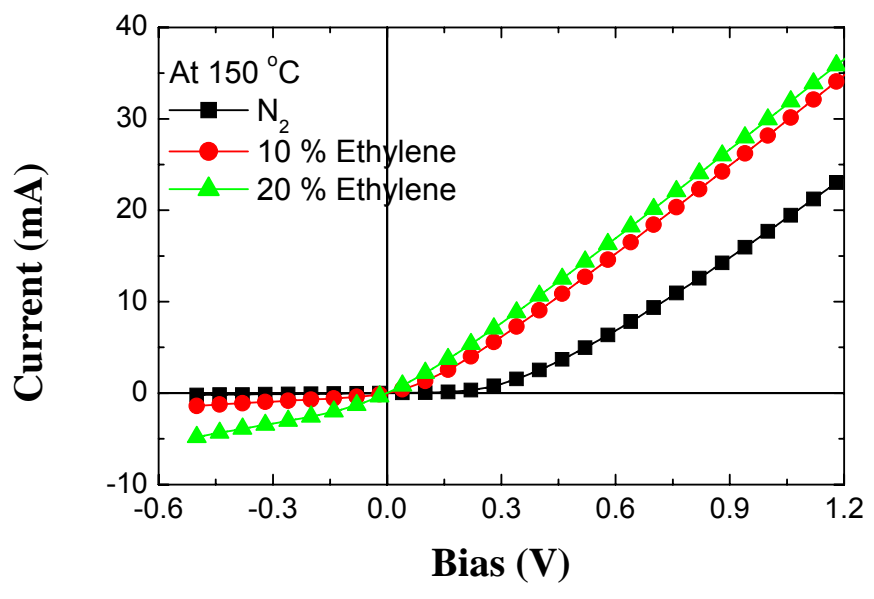

Figure 20. Change in current at a fixed bias as a function of measurement temperature in different percentages of $\mathrm{C}_{2} \mathrm{H}_{4} / \mathrm{N}_{2}$ ambients.

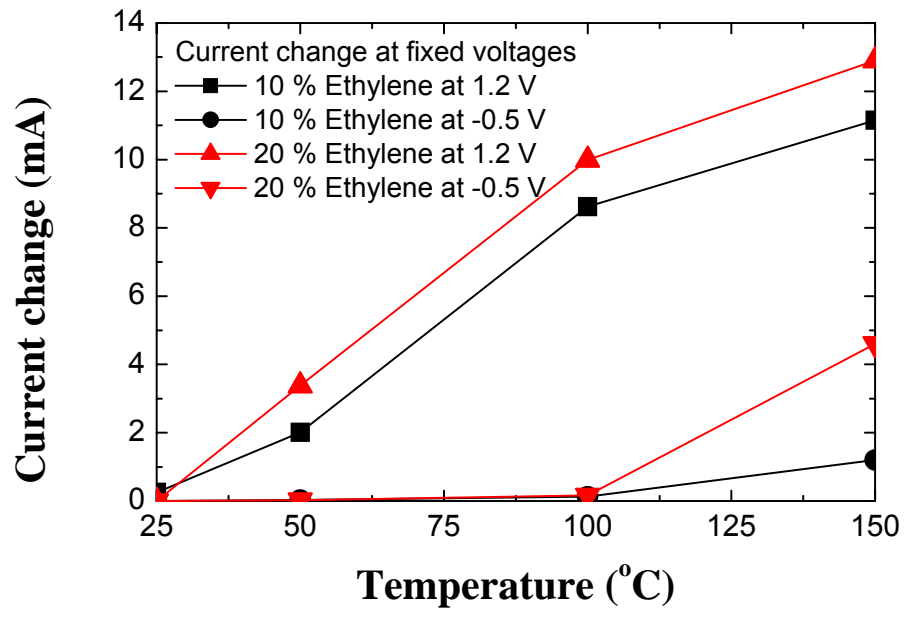

\subsection{AlGaN/GaN MOS-Diode}

AlGaN/GaN layer structures were grown on C-plane $\mathrm{Al}_{2} \mathrm{O}_{3}$ substrates by Metal Organic Chemical Vapor Deposition (MOCVD). The layer structure included an initial $2 \mu \mathrm{m}$ thick undoped GaN buffer followed by a $35 \mathrm{~nm}$ thick unintentionally doped $\mathrm{Al}_{0.28} \mathrm{Ga}_{0.72} \mathrm{~N}$ layer. The sheet carrier concentration was $\sim 1 \times 10^{13} \mathrm{~cm}^{-2}$ with a mobility of $980 \mathrm{~cm}^{2} / \mathrm{V}$-s at room temperature. Device isolation was achieved with $2,000 \AA$ plasma enhanced chemical vapor deposited $\mathrm{SiNx}$. The ohmic contacts was formed by annealing e-beam deposited Ti/Al/Pt/Au. $400 \AA \mathrm{Sc}_{2} \mathrm{O}_{3}$ was deposited as a gate dielectric through a contact window of SiNx layer. Before oxide deposition, the wafer was exposed to ozone for 25 minutes. It was then heat in-situ at $300{ }^{\circ} \mathrm{C}$ cleaning for $10 \mathrm{mins}$ inside the growth chamber. $100 \mathrm{~A} \mathrm{Sc}_{2} \mathrm{O}_{3}$ was deposited on $\mathrm{AlGaN} / \mathrm{GaN}$ by rf plasma-activated $\mathrm{MBE}$ at $100{ }^{\circ} \mathrm{C}$ using elemental $\mathrm{Sc}$ and plasma $\mathrm{O}_{2}[109,110]$. The thin Pt Schottky contact was deposited on the top of $\mathrm{Sc}_{2} \mathrm{O}_{3}$. Then, Ti/Au interconnection contacts were deposited, followed by dicing and wire-bonding. The devices were then mounted in the test chamber previously described. Figure 21 shows a schematic of the completed device. 
Figure 21. Schematic of AlGaN/GaN MOS diode.

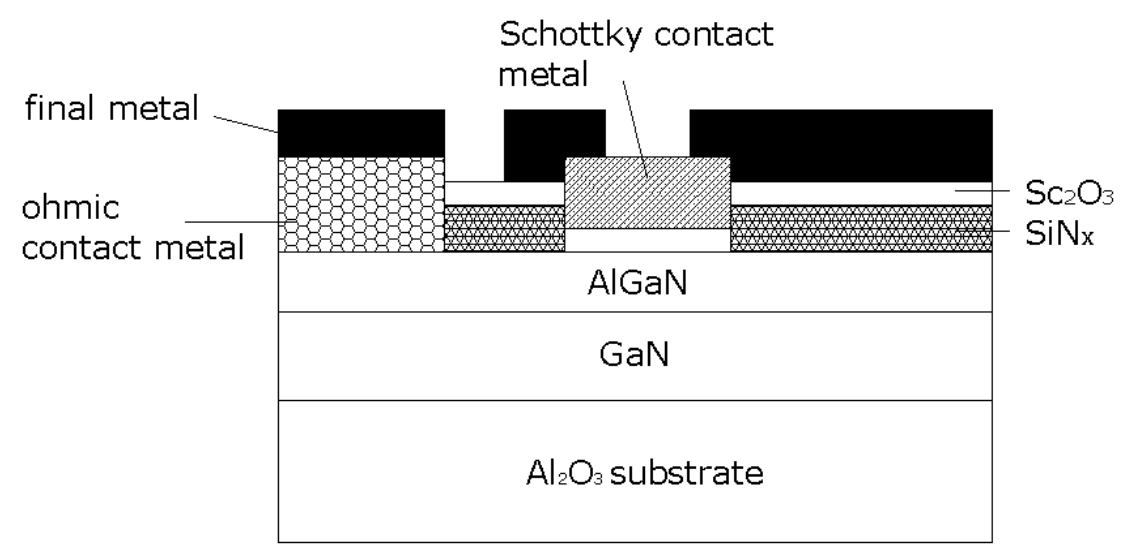

Figure 22 shows the forward diode current-voltage (I-V) characteristics at $400{ }^{\circ} \mathrm{C}$ of the $\mathrm{Pt} / \mathrm{Sc}_{2} \mathrm{O}_{3} / \mathrm{AlGaN} / \mathrm{GaN}$ MOS-HEMT diode both in pure $\mathrm{N}_{2}$ and in a $10 \% \mathrm{C}_{2} \mathrm{H}_{4} / 90 \% \mathrm{~N}_{2}$ atmosphere. The reason for testing at $400{ }^{\circ} \mathrm{C}$ will be discussed later. At a given forward bias, the current increases upon introduction of the $\mathrm{C}_{2} \mathrm{H}_{4}$. The sensing mechanism follows the same path as the hydrogen sensor Hydrogen either decomposed from $\mathrm{C}_{2} \mathrm{H}_{4}$ in the gas phase or chemisorbed on the Pt Schottky contacts then decomposed and released hydrogen. The hydrogen diffused rapidly though the Pt metallization and the underlying oxide to the interface where it forms a dipole layer and lowered the effective barrier height.

Figure 22. Forward I-V characteristics of MOS-HEMT based diode sensor at $400{ }^{\circ} \mathrm{C}$ measured under pure $\mathrm{N}_{2}$ or $10 \% \mathrm{C}_{2} \mathrm{H}_{4} / 90 \% \mathrm{~N}_{2}$ ambients.

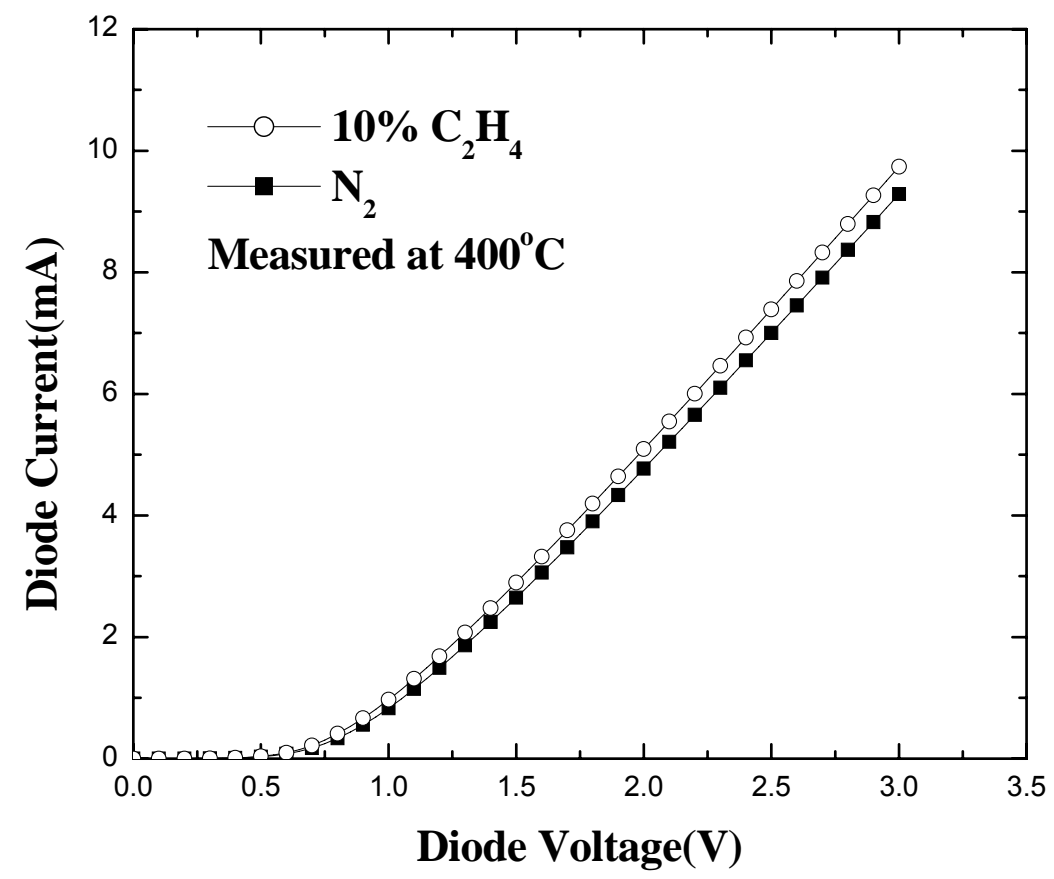


Figure 23 shows both the change in current at fixed bias as a function of temperature for the MOS diodes when switching from a $100 \% \mathrm{~N}_{2}$ ambient to $10 \% \mathrm{C}_{2} \mathrm{H}_{4} / 90 \% \mathrm{~N}_{2}$. As the detection temperature is increased, the response of the MOS-HEMT diodes increases due to more efficient cracking of the hydrogen on the metal contact. Note that the change in current is quite large and readily detected.

Figure 23 Change in MOS diode forward current at fixed forward bias of $2.5 \mathrm{~V}$ as a function of temperature for measurement in $10 \% \mathrm{C}_{2} \mathrm{H}_{4} / 90 \% \mathrm{~N}_{2}$.

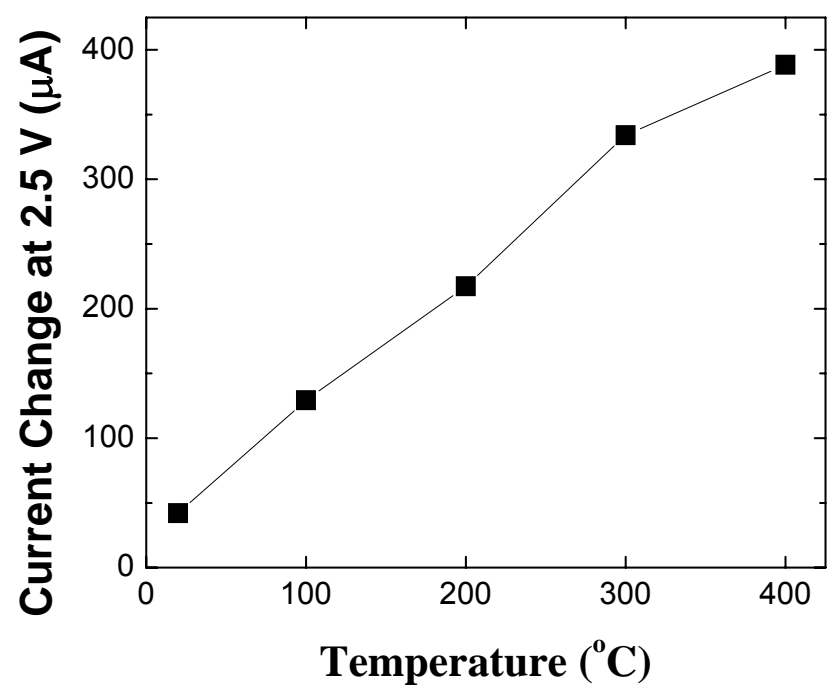

\section{Conclusions and Future Work}

$\mathrm{ZnO}$ nanorods appear well-suited to detection of $\mathrm{ppm}$ concentrations of hydrogen at room temperature. In particular, Pt-coated nanowires demonstrate a superior response compared to other metals. The recovery characteristics are fast upon removal of hydrogen from the ambient. The primary advantages of $\mathrm{ZnO}$ nanorods are that they can be placed on cheap transparent substrates such as glass, making them attractive for low-cost sensing applications and can operate at very low power conditions.

AlGaN/GaN HEMT diodes appear well-suited to combustion gas sensing applications. The changes in forward current are approximately double those of simple GaN Schottky diode gas sensors tested under similar conditions and suggest that integrated chips involving gas sensors and HEMT-based circuitry for off-chip communication are feasible in the AlGaN/GaN system. Devices show improved sensing capabilities under reverse bias polarity. Due to the amplification of the dipole layer at the interface under reverse bias conditions instead of screening under forward bias conditions, the sensitivity of hydrogen detection is higher under the reverse bias conditions. By using reverse bias condition combined with the improved stability from boride contacts, the overall stability of the GaN system is very attractive for long-term applications requiring high sensitivity. Devices show greatly improved current stability under field conditions with use of $\mathrm{Ti} / \mathrm{Al} / \mathrm{TiB} / \mathrm{Ti} / \mathrm{Au}$ contacts replacing the more conventional $\mathrm{Ti} / \mathrm{Al} / \mathrm{Pt} / \mathrm{Au}$. Combined with the superior thermal stability of these boride-based contacts, this metallization system appears attractive for sensors for long-term monitoring applications. 
We have also demonstrated PEI/starch functionalized HEMT sensors for $\mathrm{CO}_{2}$ detection with a wide dynamic range from $0.9 \%$ to $50 \%$. The sensors were operated at low bias voltage $(0.5 \mathrm{~V})$ for low power consumption applications. The sensors exhibited greater sensitivity at the testing temperature higher than $\sim 100{ }^{\circ} \mathrm{C}$. The sensors showed good repeatability. This electronic detection of $\mathrm{CO}_{2}$ gas is a significant step towards a compact sensor chip, which can be integrated with a commercially available hand-held wireless transmitter to realize a portable, fast and highly sensitive $\mathrm{CO}_{2}$ sensor.

AlGaN/GaN MOS-HEMT diodes and bulk ZnO Schottky diodes appear well-suited to detection of $\mathrm{C}_{2} \mathrm{H}_{4}$. The former have a larger temperature range of sensitivity, but the absolute changes in voltage or current are larger with the $\mathrm{ZnO}$ diodes. The introduction of hydrogen shallow donors into the nearsurface region of the $\mathrm{ZnO}$ is a plausible mechanism for the non-recovery of the I-V characteristics at room temperature.

\section{Acknowledgements}

The hydrogen sensor work at UF is partially supported by AFOSR grant under grant number F49620-03-1-0370 (T. Steiner), NSF(CTS-0301178, monitored by Dr. M. Burka and Dr. D. Senich), by NASA Kennedy Space Center Grant NAG 3-2930 monitored by Mr. Daniel E. Fitch , ONR (N00014-98-1-02-04, H. B. Dietrich), and NSF DMR 0400416. The $\mathrm{CO}_{2}$ sensor work at UF is supported by ONR Grant N000140710982 monitored by Igor Vodyanoy and the State of Florida Center of Excellence in Nano-Biosensors. The ethylene sensor work at UF is partially supported by AFOSR (F49620-02-1-0366, G. Witt and F49620-03-1-0370), NSF (CTS-0301178, monitored by Dr. M. Burka and Dr. D. Senich), by NASA Kennedy Space Center Grant NAG 10-316 monitored by Mr. Daniel E. Fitch, ONR (N00014-98-1-02-04, H. B. Dietrich), and NSF DMR 0101438.

\section{References and Notes}

1. Zhang, A.P.; Rowland, L.B.; Kaminsky, E.B.; Tucker, J.B.; Kretchmer, J.W.; Allen, A.F.; Cook, J.; Edward, B.J. 9.2W/mm (13.8W) AlGaN/GaN HEMTs at $10 \mathrm{GHz}$ and $55 \mathrm{~V}$ drain bias. Electron. Lett. 2003, 39, 245-247.

2. Saito, W.; Takada, Y.; Kuraguchi, M.; Tsuda, K.; Omura, I.; Ogura, T.; Ohashi, H. High breakdown voltage AlGaN-GaN Power-HEMT design and high current density switching behavior. IEEE Trans. Electron. Dev. 2003, 50, 2528-2531.

3. Zhang, A.P.; Rowland, L.B.; Kaminsky, E.B.; Tilak, V.; Grande, J.C.; Teetsov, J.; Vertiatchikh, A.; Eastman, L.F. Correlation of device performance and defects in AlGaN/GaN high-electron mobility transistors. J. Electron. Mater. 2003, 32, 388-394.

4. Lu, W.; Kumar, V.; Piner, E.L.; Adesida, I. DC, RF, and, microwave noise performance of AlGaN-GaN field effect transistors dependence of aluminum concentration. IEEE Trans. Electron. Dev. 2003, 50, 1069-1074.

5. Valizadeh, P.; Pavlidis, D. Investigation of the impact of Al mole-fraction on the consequences of RF stress on AlxGa1-xN/GaN MODFETs. IEEE Trans. Electron. Dev. 2005, 52, 1933-1939.

6. Pearton, S.J.; Zolper, J.C.; Shul, R.J.; Ren, F. GaN: processing, defects, and devices. J. Appl. Phys. 1999, 86, 1-78 and references therein. 
7. Hikita, M.; Yanagihara, M.; Nakazawa, K.; Ueno, H.; Hirose, Y.; Ueda, T.; Uemoto, Y.; Tanaka, T.; Ueda, D.; Egawa, T. AlGaN/GaN power HFET on silicon substrate with source-via grounding (SVG) structure. IEEE Trans. Electron. Dev. 2005, 52, 1963-1968.

8. Nakazawa, S.; Ueda, T.; Inoue, K.; Tanaka, T.; Ishikawa, H.; Egawa, T. Recessed-gate AlGaN/GaN HFETs with lattice-matched InAlGaN quaternary alloy capping layers. IEEE Trans. Electron. Dev. 2005, 52, 2124-2128.

9. Palacios, T.; Rajan, S.; Chakraborty, A.; Heikman, S.; Keller, S.; DenBaars, S. P.; Mishra, U.K. Influence of the dynamic access resistance in the $\mathrm{g}(\mathrm{m})$ and $\mathrm{f}(\mathrm{T})$ linearity of AlGaN/GaN HEMTs. IEEE Trans. Electron. Dev. 2005, 52, 2117-2123.

10. Mishra, U.K.; Parikh, P.; Wu, Y.F. AlGaN/GaN HEMTs - An overview of device operation and applications. Proc. IEEE 2002, 90, 1022-1031.

11. Eastman, L.F.; Tilak, V.; Smart, J.; Green, B.M.; Chumbes, E.M.; Dimitrov, R.; Kim, H.; Ambacher, O.S.; Weimann, N.; Prunty, T.; Murphy, M.; Schaff, W.J.; Shealy, J.R. Undoped AlGaN/GaN HEMTs for microwave power amplification. IEEE Trans. Electron Dev. 2001, 48, 479-485.

12. Keller, S.; Wu, Y.-F.; Parish, G.; Ziang, N.; Xu, J.J.; Keller, B.P.; DenBaars, S.P.; Mishra, U.K. Gallium nitride based high power heterojunction field effect transistors: Process development and present status at UCSB. IEEE Trans. Electron. Dev. 2001, 48, 552-559.

13. Adivarahan, V.; Gaevski, M.; Sun, W.H.; Fatima, H.; Koudymov, A.; Saygi, S.; Simin, G.; Yang, J.; Khan, M.A.; Tarakji, A.; Shur, M.S.; Gaska, R. Submicron gate $\mathrm{Si}_{3} \mathrm{~N}_{4} / \mathrm{AlGaN} / \mathrm{GaN}-\mathrm{metal}-$ insulator-semiconductor heterostructure field-effect transistors. IEEE Electron. Device Lett. 2003, 24, 541-543.

14. Tarakji, A.; Fatima, H.; Hu, X.; Zhang, J.P.; Simin, G.; Khan, M.A.; Shur, M.S.; Gaska, R. Largesignal linearity in III-N MOSDHFETs. IEEE Electron Dev. Lett. 2003, 24, 369-371.

15. Iwakami, S.; Yanagihara, M.; Machida, O.; Chino, E.; Kaneko, N.; Goto, H.; Ohtsuka, K. $\mathrm{AlGaN} / \mathrm{GaN}$ heterostructure field-effect transistors (HFETs) on Si substrates for large-current operation. Jpn. J. Appl. Phys. 2004, 43, L831-L833.

16. Mehandru, R.; Kim, S.; Kim, J.; Ren, F.; Lothian, J.; Pearton, S.J.; Park, S.S.; Park, Y.J. Thermal simulations of high power, bulk GaN rectifiers. Solid-State Electron. 2003, 47, 1037-1043.

17. Luther, B.P.; Wolter, S.D.; Mohney, S.E. High temperature Pt Schottky diode gas sensors on ntype GaN. Sens. Actuat. B 1999, 56, 164-168.

18. Baranzahi, A.; Spetz, A.L.; Lundström, I. Reversible hydrogen annealing of metal-oxide-silicon carbide devices at high-temperatures. Appl. Phys. Lett. 1995, 67, 3203-3205.

19. Schalwig, J.; Muller, G.; Ambacher, O.; Stutzmann, M. Group-III-nitride based gas sensing devices. Phys. Status Solidi. A 2001, 185, 39-45.

20. Schalwig, J.; Muller, G.; Eickhoff, M.; Ambacher, O.; Stutzmann, M. Gas sensitive GaN/AlGaNheterostructures. Sens. Actuat. B 2002, 87, 425-430.

21. Kim, J.; Ren, F.; Gila, B.; Abernathy, C.R.; Pearton, S.J. Reversible barrier height changes in hydrogen-sensitive Pd/GaN and Pt/GaN diodes. Appl. Phys. Lett. 2003, 82, 739-741. 
22. Wang, H.T.; Kang, B.S.; Ren, F.; Fitch, R.C.; Gillespie, J.; Moser, N.; Jessen, G.; Dettmer, R.; Gila, B.P.; Abernathy, C.R.; Pearton, S.J. Comparison of gate and drain current detection of hydrogen at room temperature with $\mathrm{AlGaN} / \mathrm{GaN}$ high electron mobility transistors. Appl. Phys. Lett. 2005, 87, 172105.

23. Kouche, A.E.L.; Lin, J.; Law, M.E.; Kim, S.; Kang, B.S.; Ren, F.; Pearton, S.J. Remote sensing system for hydrogen using GaN Schottky diodes. Sens. Actuat. B: Chem. 2005, 105, 329-333.

24. Kang, B.S.; Mehandru, R.; Kim, S.; Ren, F.; Fitch, R.; Gillespie, J.; Moser, N.; Jessen, G.; Jenkins, T.; Dettmer, R.; Via, D.; Crespo, A.; Gila, B.P.; Abernathy, C.R.; Pearton, S.J. Hydrogen-induced reversible changes in drain current in Sc2O3/AlGaN/GaN high electron mobility transistors. Appl. Phys. Lett. 2004, 84, 4635-4637.

25. Kang, B.S.; Ren, F.; Gila, B.P.; Abernathy, C.R.; Pearton, S.J. AlGaN/GaN-based metal-oxidesemiconductor diode-based hydrogen gas sensor. Appl. Phys. Lett. 2004, 84, 1123-1125.

26. Kim, J.; Gila, B.; Chung, G.Y.; Abernathy, C.R.; Pearton, S.J.; Ren, F. AlGaN/GaN-based metaloxide-semiconductor diode-based hydrogen gas sensor. Solid-State Electron. 2003, 47, 10691073.

27. Huang, J.R.; Hsu, W.C.; Chen, Y.J.; Wang, T.-B.; Lin, K.W.; Chen, H.-I.; Liu, W.-C. Comparison of hydrogen sensing characteristics for $\mathrm{Pd} / \mathrm{GaN}$ and $\mathrm{Pd} / \mathrm{Al} 0.3 \mathrm{Ga} 0.7 \mathrm{As}$ Schottky diodes. Sens. Actuat. B 2006, 117, 151-158.

28. Kang, B.S.; Kim, S.; Ren, F.; Gila, B.P.; Abernathy, C.R.; Pearton, S.J. Comparison of MOS and Schottky W/Pt-GaN diodes for hydrogen detection. Sens. Actuat. B 2005, 104, 232-236.

29. Matsuo, K.; Negoro, N.; Kotani, J.; Hashizume, T.; Hasegawa, H. Pt Schottky diode gas sensors formed on GaN and AlGaN/GaN heterostructure. Appl. Surf. Sci. 2005, 244, 273-276.

30. Song, J.; Lu, W.; Flynn, J.S.; Brandes, G.R. AlGaN/GaN Schottky diode hydrogen sensor performance at high temperatures with different catalytic metals. Solid-State Electron. 2005, 49, 1330-1334.

31. Weidemann, O.; Hermann, M.; Steinhoff, G.; Wingbrant, H.; Spetz, A.L.; Stutzmann, M.; Eickhoff, M. Influence of surface oxides on hydrogen-sensitive Pd:GaN Schottky diodes. Appl. Phys. Lett. 2003, 83, 773-775.

32. Ali, M.; Cimalla, V.; Lebedev, V.; Romanus, H.; Tilak, V.; Merfeld, D.; Sandvik, P.; Ambacher, O. Pt/GaN Schottky diodes for hydrogen gas sensors. Sens. Actuat. B 2006, 113, 797-804.

33. Voss, L.; Gila, B.P.; Pearton, S.J.; Wang, H.-T.; Ren, F. Characterization of bulk GaN rectifiers for hydrogen gas sensing. J. Vac. Sci. Technol. B 2005, 3, 2373-2377.

34. Song, J.; Lu, W.; Flynn, J.S.; Brandes, G.R. Pt-AlGaN/GaN Schottky diodes operated at $800{ }^{\circ} \mathrm{C}$ for hydrogen sensing. Appl. Phys. Lett. 2005, 87, 133501.

35. Yun, F.; Chevtchenko, S.; Moon, Y. -T.; Morkoç, H.; Fawcett, T.J.; Wolan, J.T. GaN resistive hydrogen gas sensors. Appl. Phys. Lett. 2005, 87, 073507.

36. Schalwig, J.; Muller, G.; Eickhoff, M.; Ambacher, O.; Stutzmann, M. Gas sensitive GaN/AlGaNheterostructures. Sens. Actuat. B 2002, 81, 425-430.

37. Eickhoff, M.; Schalwig, J.; Steinhoff, G.; Weidmann, O.; Gorgens, L.; Neuberger, R.; Hermann, M.; Baur, B.; Muller, G.; Ambacher, O.; Stutzmann, M. Electronics and sensors based on pyroelectric $\mathrm{AlGaN} / \mathrm{GaN}$ heterostructures - Part B: Sensor applications. Phys. Stat. Solidi C 2003, 6, 1908-1918. 
38. Svenningstorp, H.; Tobias, P.; Lundström, I.; Salomonsson, P.; Mårtensson, P.; Ekedahl, L.-G.; Spetz, A.L. Influence of catalytic reactivity on the response of metal-oxide-silicon carbide sensor to exhaust gases. Sens. Actuat. B: Chem. 1999, B57, 159-165.

39. Chen, L.; Hunter, G.W.; Neudeck, P.G. X-ray photoelectron spectroscopy study of the heating effects on Pd/6H-SiC Schottky structure. J. Vac. Sci. Technol A 1997, 15, 1228-1234.

40. Baranzahi, A.; Spetz, A.L.; Lundström, I. Reversible hydrogen annealing of metal-oxide-silicon carbide devices at high temperatures. Appl. Phys. Lett. 1995, 67, 3203-3205.

41. Kang, B.S.; Mehandru, R.; Kim, S.; Ren, F.; Fitch, R.; Gillespie, J.; Moser, N.; Jessen, G.; Jenkins, T.; Dettmer, R.; Via, D.; Crespo, A.; Gila, B.P.; Abernathy, C.R.; Pearton, S.J. Hydrogen-induced reversible changes in drain current in Sc2O3/AlGaN/GaN high electron mobility transistors. Appl. Phys. Lett. 2004, 84, 4635-4637.

42. Kang, B.S.; Heo, Y.W.; Tien, L.C.; Norton, D.P.; Ren, F.; Gila, B.P.; Pearton, S.J. Electrical transport properties of single $\mathrm{ZnO}$ nanorods. Appl. Phys. A 2005, 80, 1029-1032.

43. Kouche, A.El.; Lin, J.; Law, M.E.; Kim, S.; Kim, B.S.; Ren, F.; Pearton, S.J. Remote sensing system for hydrogen using GaN Schottky diodes. Sens. Actuat. B: Chem. 2005, 105, 329-333.

44. Pearton, S.J.; Kang, B.S.; Kim, S.; Ren, F.; Gila, B.P.; Abernathy, C.R.; Lin, J.; Chu, S.N.G. GaN-based diodes and transistors for chemical, gas, biological and pressure sensing. J. Phys: Condens. Matt. 2004, 16, R961-R994.

45. Kim, S.; Kang, B.; Ren, F.; Ip, K.; Heo, Y.; Norton, D.; Pearton, S.J. Sensitivity of Pt/ZnO Schottky diode characteristics to hydrogen. Appl. Phys. Lett. 2004, 84, 1698-1700.

46. Kang, B.S.; Wang, H.T.; Ren, F.; Gila, B.P.; Abernathy, C.R.; Pearton, S.J.; Johnson, J.W.; Rajagopal, P.; Roberts, J.C.; Piner, E.L.; Linthicum, K.J. pH sensor using AlGaN/GaN high electron mobility transistors with $\mathrm{Sc}_{2} \mathrm{O}_{3}$ in the gate region. Appl. Phys. Lett. 2007, 91, 012110.

47. Kang, B.S.; Wang, H.T.; Ren, F.; Pearton, S.J.; Morey, T.E.; Dennis, D.M.; Johnson, J.W.; Rajagopal, P.; Roberts, J.C.; Piner, E.L.; Linthicum, K.J. Enzymatic glucose detection using ZnO nanorods on the gate region of $\mathrm{AlGaN} / \mathrm{GaN}$ high electron mobility transistors. Appl. Phys. Lett. 2007, 91, 252103.

48. Kang, B.S.; Wang, H.T.; Lele, T.P.; Tseng, Y.; Ren, F.; Pearton, S.J.; Johnson, J.W.; Rajagopal, P.; Roberts, J.C.; Piner, E.L.; Linthicum, K.J. Prostate specific antigen detection using AlGaN/GaN high electron mobility transistors. Appl. Phys. Lett. 2007, 91, 112106.

49. Wang, H.T.; Kang, B.S.; Ren, F.; Pearton, S.J.; Johnson, J.W.; Rajagopal, P.; Roberts, J.C.; Piner, E.L.; Linthicum, K.J. Electrical detection of kidney injury molecule-1 with $\mathrm{AlGaN} / \mathrm{GaN}$ high electron mobility transistors. Appl. Phys. Lett. 2007, 91, 222101.

50. Vasiliev, A.; Moritz, W.; Fillipov, V.; Bartholomäus, L.; Terentjev, A.; Gabusjan, T. High temperature semiconductor sensor for the detection of fluorine. Sens. Actuat. B 1998, 49, 133-138.

51. Kim, J.; Ren, F.; Gila, B.; Abernathy, C.R.; Pearton, S.J. Reversible barrier height changes in hydrogen-sensitive Pd/GaN and Pt/GaN diodes. Appl. Phys. Lett. 2003, 82, 739-741.

52. Kim, J.; Gila, B.; Abernathy, C.R.; Chung, G.Y.; Ren, F.; Pearton, S.J. Comparison of Pt/GaN and $\mathrm{Pt} / 4 \mathrm{H}-\mathrm{SiC}$ Gas Sensors. Solid State Electron. 2003, 47, 1487-1490.

53. Spetz, A.L.; Tobias, P.; Unéus, L.; Svenningstorp, H.; Ekedahl, L.-G.; Lundström, I. High temperature catalytic metal field effect transistors for industrial applications. Sens. Actuat. B 2000, $70,67-76$. 
54. Connolly, E.J.; O'Halloran, G.M.; Pham, H.T.M.; Sarro, P.M.; French, P.J. Comparison of porous silicon, porous polysilicon and porous silicon carbide as materials for humidity sensing applications. Sens. Actuat. A 2002, 99, 25-30.

55. Hunter, G.W.; Neudeck, P.G.; Okojie, R.S.; Beheim, G.M.; Thomas, V.; Chen, L.; Lukco, D.; Liu, C.C.; Ward, B.; Makel, D. Development of. SiC gas sensor systems. Proc. ECS 2002, 3, 93-111.

56. Neuberger, R.; Muller, G.; Ambacher, O.; Stutzmann, M. High electron mobility AlGaN/GaN transistors for fluid monitoring applications. Phys. Status Solidi. A 2001, 185, 85-89.

57. Schalwig, J.; Muller, G.; Ambacher, O.; Stutzmann, M. Group-III-nitride based sensing devices. Phys. Status Solidi. A 2001, 185, 39-45.

58. Steinhoff, G.; Hermann, M.; Schaff, W.J.; Eastmann, L.F.; Stutzmann, M.; Eickhoff, M. pH response of $\mathrm{GaN}$ surfaces and its application for $\mathrm{pH}$-sensitive field-effect transistors. Appl. Phys. Lett. 2003, 83, 177-179.

59. Eickhoff, M.; Neuberger, R.; Steinhoff, G.; Ambacher, O.; Muller, G.; Stutzmann, M. Wetting behaviour of GaN-surfaces with Ga- or N-face polarity. Phys. Status Solidi B 2001, 228, 519-522.

60. Lu, Y.; Li, J.; Ng, H.T.; Binder, C.; Partridge, C.; Meyyapan, M. Room temperature methane detection using palladium loaded single-walled carbon nanotube sensors. Chem. Phys. Lett. 2004, 391, 344-348.

61. Sayago, I.; Terrado, E.; Lafuente, E.; Horillo, M.C.; Maser, W.K.; Benito, A.M.; Navarro, R.; Urriolabeita, E.P.; Martinez, M.T.; Gutierrez, J. Hydrogen sensors based on carbon nanotubes thin films. Syn. Metals 2005, 148, 15-19.

62. Kang, B.S.; Ren, F.; Heo, Y.W.; Tien, L.C.; Norton, D.P.; Pearton, S.J. pH measurements with single $\mathrm{ZnO}$ nanorods integrated with a microchannel. Appl. Phys. Lett. 2005, 86, 112105.

63. Wan, Q.; Li, Q.H.; Chen, Y.J.; Wang, T.H.; He, X.L.; Li, J.P.; Lin, C.L. Fabrication and ethanol sensing characteristics of $\mathrm{ZnO}$ nanowire gas sensors. Appl. Phys. Lett. 2004, 84, 3654-3656.

64. Wan, Q.; Li, Q.H.; Chen, Y.J.; Wang, T.H.; He, X.L.; Gao, X.G.; Li, J.P. Positive temperature coefficient resistance and humidity sensing properties of Cd-doped $\mathrm{ZnO}$ nanowires. Appl. Phys. Lett. 2004, 84, 3085-3087.

65. Keem, K.; Kim, H.; Kim, G.T.; Lee, J.S.; Min, B.; Cho, K.; Sung, M.Y.; Kim, S. Photocurrent in $\mathrm{ZnO}$ nanowires grown from Au electrodes. Appl. Phys. Lett. 2004, 84, 4376-4378.

66. Huang, M.H.; Mao, S.; Feick, H.; Yan, H.; Wu, Y.; Kind, H.; Weber, E. Russo, R.; Yang, P. Room-temperature ultraviolet nanowire nanolasers. Science 2001, 292, 1897-1899.

67. Wang, Z.L. Nanostructures of zinc oxide. Mat. Today 2004, 7, 26-33.

68. Heo, Y.W.; Norton, D.P.; Tien, L.C.; Kwon, Y.; Kang, B.S.; Ren, F.; Pearton, S.J.; LaRoche, J.R. $\mathrm{ZnO}$ nanowire growth and devices. Mat. Sci. Eng. R 2004, 47, 1-47.

69. Liu, C.H.; Liu, W.C.; Au, F.C.K.; Ding, J.X.; Lee, C.S.; Lee, S.T. Electrical properties of zinc oxide nanowires and intramolecular p-n junctions. Appl. Phys. Lett. 2003, 83, 3168-3170.

70. Park, W.I.; Yi, G.C.; Kim, J.W.; Park, S.M. Schottky nanocontacts on ZnO nanorod arrays. Appl. Phys. Lett. 2003, 82, 4358-4360.

71. Ng, H.T.; Li, J.; Smith, M.K.; Nguygen, P.; Cassell, A.; Han, J.; Meyyappan, M. Growth of epitaxial nanowires at the junctions of nanowalls. Science 2003, 300, 1249.

72. Park, W.I.; Yi, G.C.; Kim, M.Y.; Pennycook, S.J. Quantum confinement observed in $\mathrm{ZnO} / \mathrm{ZnMgO}$ nanorod heterostructures. Adv. Mater. 2003, 15, 526-529. 
73. Poole, P.J.; Lefebvre, J.; Fraser, J. Spatially controlled, nanoparticle-free growth of InP nanowires. Appl. Phys. Lett. 2003, 83, 2055-2057.

74. He, M.; Fahmi, M. M. E.; Mohammad, S.N.; Jacobs, R. N.; Salamanca-Riba, L.; Felt, F.; Jah, M.; Sharma, A.; Lakins, D. InAs nanowires and whiskers grown by reaction of indium with GaAs. Appl. Phys. Lett. 2003, 82, 3749-3751.

75. Wu, X.C.; Song, W.H.; Huang, W.D.; Pu, M.H.; Zhao, B.; Sun, Y.P.; Du, J.J. Crystalline gallium oxide nanowires: intensive blue light emitters. Chem. Phys. Lett. 2000, 328, 5-9.

76. Zheng, M.J.; Zhang, L.D.; Li, G.H.; Zhang, X.Y.; Wang, X.F. Ordered indium-oxide nanowire arrays and their photoluminescence properties. Appl. Phys. Lett. 2001, 79, 839-841.

77. Zhang, B.P.; Binh, N.T.; Segawa, Y.; Wakatsuki, K.; Usami, N. Optical properties of ZnO rods formed by metalorganic chemical vapor deposition. Appl. Phys. Lett. 2003, 83, 1635-1637.

78. Park, W.I.; Jun, Y.H.; Jung, S.W.; Yi, G. Excitonic emissions observed in ZnO single crystal nanorods. Appl. Phys. Lett. 2003, 82, 964-966.

79. Pan, Z.W.; Dai, Z.R.; Wang, Z.L. Nanobelts of semiconducting oxides. Science 2001, 291, 19471949.

80. Lao, J.Y.; Huang, J.Y.; Wang, D.Z.; Ren, Z.F. ZnO Nanobridges and Nanonails. Nano Lett. 2003, 3, 235-238.

81. Wang, H.T.; Anderson, T.J.; Ren, F.; Li, C.; Now, Z.N.; Lin, J.; Gila, B.P.; Pearton, S.J.; Osinsky, A.; Dabiran, A. Robust detection of hydrogen using differential AlGaN/GaN high electron mobility transistor sensing diodes. Appl. Phys. Lett. 2006, 89, 242111.

82. Khanna, R.; Pearton, S.J.; Ren, F.; Kravchenko, I.I. Comparison of electrical and reliability performances of $\mathrm{TiB}_{2^{-}}, \mathrm{CrB}_{2^{-}}$, and $\mathrm{W}_{2} \mathrm{~B}_{5}$-based Ohmic contacts on $\mathrm{n}-\mathrm{GaN}$. J. Vac. Sci. Technol. 2006, B24, 744-748.

83. Mitra, P.; Chatterjee, A.P.; Maiti, H.S. ZnO thin film sensor. Mater. Lett. 1998, 35, 33-38.

84. Hartnagel, H.L.; Dawar, A.L.; Jain, A.K.; Jagadish, C. Semiconducting Transparent Thin Films. IOP Publishing: Bristol, England, UK, 1995.

85. Chang, J.F.; Kuo, H.H.; Leu, I.C.; Hon, M.H. The effects of thickness and operation temperature on $\mathrm{ZnO}$ : Al thin film CO gas sensor. Sens. Actuat. B 1994, 84, 258-264.

86. See the data bases at http://www. rebresearch. com/H2perm2. htm and http://www. rebresearch. com/H2sol2. htm

87. Eberhardt, W.; Greunter, F.; Plummer, E.W. Bonding of H to Ni, Pd, and Pt Surfaces. Phys. Rev. Lett. 1981, 46, 1085-1088.

88. Voss L.; Gila, B.P.; Pearton, S.J.; Wang, H.-T.; Ren, F. Characterization of bulk GaN rectifiers for hydrogen gas sensing. J. Vac. Sci. Technol. B 2005, 23, 2373-2377 .

89. Wang, H.-T.; Kang, B.S.; Ren, F.; Fitch, R.C.; Gillespie, J.K.; Moser, N.; Jessen, G.; Jenkins, T.; Dettmer, R.; Via, D.; Crespo, A.; Gila, B.P.; Abernathy, C.R.; Pearton, S.J. Comparison of gate and drain current detection of hydrogen at room temperature with AlGaN/GaN high electron mobility transistors. Appl. Phys. Lett. 2005, 87, 172105.

90. Hung, C.W.; Lin, H.-L.; Chen, H.-I.; Tsai, Y.-Y.; Lai, P.H.; Fu, S.-I.; Liu, W.-C. A Novel Pt/In0.52A10.48As Schottky Diode-Type Hydrogen Sensor. Electron. Dev. Lett. 2006, 27, 951-954. 
91. Koudymov, A.; Shur, M.S.; Simin, G.; Gaska, R. Current collapse and reliability of III-N heterostructure field effect transistors. Phys. Stat. Solidi R 2007, 3, 116-118.

92. Thorpe, M.J.; Moll, K.D.; Jones, R.J.; Safdi, B.; Ye, J. Broadband cavity ringdown spectroscopy for sensitive and rapid molecular detection. Science. 2006, 311, 1595-1599.

93. Thorpe, M.J.; Balslev-Clausen, D.; Kirchner, M.S.; Ye, J. Cavity-enhanced optical frequency comb spectroscopy: application to human breath analysis. Opt. Express 2008, 16, 2387-2397.

94. Namjou, K.; Roller, C.B.; McCann, P.J. A new laser device to analyze your health. IEEE Circuits Dev. 2006, 22, 22-26.

95. Machado, R.F.; Laskowski, D.; Deffenderfer, O.; Burch, T.; Zheng, S.; Mazzone, P.J.; Mekhail, T.; Jennings, C.; Stoller, J.K.; Pyle, J. Detection of lung cancer by sensor array analyses of exhaled breath. Am. J., Respir. Crit. Care. Med. 2005, 171, 1286-1291.

96. Rye, B.J. Infrared Methods for Gaseous Measurements; Marcel Dekker: New York, NY, USA. 1985.

97. Manuccia, T.J.; Eden, J.G. Infrared optical measurement of blood gas concentrations and fiber optical catheter, USA Pat. 4509522, 1985.

98. Chu, C.S.; Lo, Y.L. Fiber-optic carbon dioxide sensor based on fluorinated xerogels doped with HPTS. Sens. Actuat. B: Chem. 2008, 129, 120-125.

99. Kimmig, L.; Krause, P.; Ludwig, M.; Schmidt, K. Non-dispersive infrared gas analyzer, USA Patent 6, 2000, 166, 383.

100. Zhou, R.; Hierlemann, A.; Weimar, U.; Schmeiber, D.; Gopel, W. Mass sensitive detection of $\mathrm{co}_{2}$ by aminogroup-functionionalized polymers. The 8th International Conference on Solid-State Sensors and Actuators, and Eurosensors IX. Stockholm, Sweden, June 25-29, 1995; 225, PD6.

101. Shim, M.; Javey, A.; Kam, N.W.S.; Dai, H. Polymer functionalization for air-stable n-type carbon nanotube field-effect transistors. J. Am. Chen. Soc. 2001, 123, 11512-11513.

102. Kong, J.; Dai, H. Full and modulated chemical gating of individual carbon nanotubes by organic amine compounds. J. Phys. Chem. B 2001, 105, 2890-2893.

103. Satyapal, S.; Filburn, T.; Trela, J.; Strange, J. Performance and properties of a solid amine sorbent for carbon dioxide removal in space life support applications. Energ. Fuel 2001, 15, 250-255.

104. Dell'Amico, D.B.; Calderazzo, F.; Labella, L.; Marchetti, F.; Pampaloni, G. Converting carbon dioxide into carbamato derivatives. Chem. Rev. 2003, 103, 3857-3897.

105. Ong, K.G.; Grimes, C.A. A Carbon nanotube-based sensor for $\mathrm{CO}_{2}$ monitoring. Sensors 2001, 1, 193-205.

106. Varghese, O.K.; Kichambre, P.D.; Gong, D.; Ong, K.G.; Dickey, E.C.; Grimes, C.A. Gas sensing characteristics of multi-wall carbon nanotubes. Sens. Actuat. B: Chem. 2001, 81, 32-41.

107. Star, A.; Han, T.R.; Joshi, V.; Gabriel, J.P.; Gruner, G. Nanoelectronic carbon dioxide sensors. Adv. Mater. 2004, 16, 2049-2052.

108. Kuzmych, O.; Allen, B.L.; Star, A. Carbon nanotube sensors for exhaled breath components. Nanotechnology 2007, 18, 375502.

109. Gila, B.P.; Johnson, J.W.; Mehandru, R.; Luo, B.; Onstine, A.H.; Krishnamoorthy, V.; Bates, S.; Abernathy, C.R.; Ren, F.; Pearton, S.J. Gadolinium Oxide and Scandium Oxide: Gate Dielectrics for GaN MOSFETs. Phys. Stat. Solid A 2001, 188, 239-242. 
110. Kim, J.; Mehandru, R.; Luo, B.; Ren, F.; Gila, B.P.; Onstine, A.H.; Abernathy, C.R.; Pearton, S.J.; Irokawa, Y. Characteristics of $\mathrm{MgO} / \mathrm{GaN}$ gate-controlled metal-oxide-semiconductor diodes. Appl. Phys. Lett. 2002, 80, 4555-4557.

(C) 2009 by the authors; licensee Molecular Diversity Preservation International, Basel, Switzerland. This article is an open-access article distributed under the terms and conditions of the Creative Commons Attribution license (http://creativecommons. org/licenses/by/3. 0/). 